http://dx.doi.org/10.22265/acnef.7.Supl.2.473

\title{
Consenso colombiano de expertos sobre recomendaciones informadas en la evidencia para la prevención, el diagnóstico y el manejo de la lesión renal aguda por SARS-CoV-2/COVID-19
}
Colombian consensus of experts on recommendations informed in the evidence for the prevention, diagnosis and management of acute kidney injury by SARS-CoV-2 / COVID-19

(ㄷ) Camilo González ${ }^{1,2,3,4}{ }^{\oplus}$ Erika Yama $^{1,2,3},{ }^{\odot}$ Nancy Yomayusa ${ }^{1,3}$, ${ }^{\odot}$ Juan Vargas ${ }^{1,2}$, ${ }^{\oplus}$ Jorge Rico ${ }^{1,5}$, ${ }^{\oplus}$ Amaury Ariza ${ }^{1,6},{ }^{\bullet}$ Gustavo Aroca ${ }^{1,7},{ }^{\oplus}$ Richard Baquero ${ }^{8,9},{ }^{\circ}$ Roberto Ramírez ${ }^{1},{ }^{\odot}$ Kelly Chacón ${ }^{3}$, ${ }^{\bullet}$ Rodolfo Torres ${ }^{1,2},{ }^{\oplus}$ Adriana Robayo ${ }^{1},{ }^{\oplus}$ Adalberto Peña ${ }^{1,10},{ }^{\oplus}$ Adriana Meza ${ }^{7,11},{ }^{\circ}$ Alejandra Molano ${ }^{1}$, ${ }^{\circ}$ Alexandra Lizarazo ${ }^{1},{ }^{\oplus}$ Andrea Caicedo ${ }^{1},{ }^{\oplus}$ Andrés Acevedo ${ }^{1,2},{ }^{\oplus}$ Angélica Calderón ${ }^{7,12}$, Betty Zambrano ${ }^{2}$, (ㄷ) Carlos Guido Musso ${ }^{13}$, Carlos Lozano ${ }^{1},{ }^{\oplus}$ Cristóbal Buitrago ${ }^{14},{ }^{\oplus}$ David Ballesteros ${ }^{1,15},{ }^{\oplus}$ Diana Chacón ${ }^{7,16}$,

${ }^{\circ}$ Diana Vargas ${ }^{1},{ }^{\oplus}$ Diana Gayón ${ }^{1},{ }^{\oplus}$ Douglas Villafañe ${ }^{7,17}$, Francisco López ${ }^{1}$, Freddy Ardila ${ }^{1,18}$,

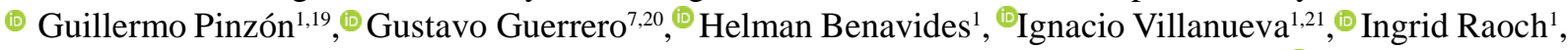

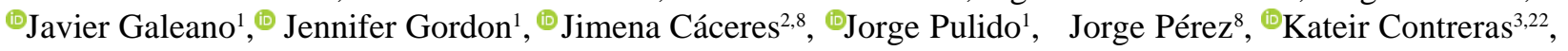
${ }^{-}$Leidy Aristizábal ${ }^{23}$, Luis Valderrama ${ }^{1}$, María Gómez ${ }^{1}$, ${ }^{-M a r i ́ a ~ J o s e ́ ~ V a r g a s ~}{ }^{24}$, ${ }^{\odot}$ Martha Carrascal ${ }^{7,25}$, ${ }^{\circledR}$ Martha Rodríguez ${ }^{4,26}$, Mauricio Guerrero ${ }^{1},{ }^{\oplus}$ Mercedes Alfaro $^{1}$, Natalia Tobón ${ }^{1},{ }^{\oplus}$ Paola García ${ }^{1,3}$, ${ }^{\circ}$ Paula Rodríguez ${ }^{1}{ }^{\oplus}$ Rodrigo Daza ${ }^{1,5},{ }^{\oplus}$ Zilac Espitaleta ${ }^{7,8}$

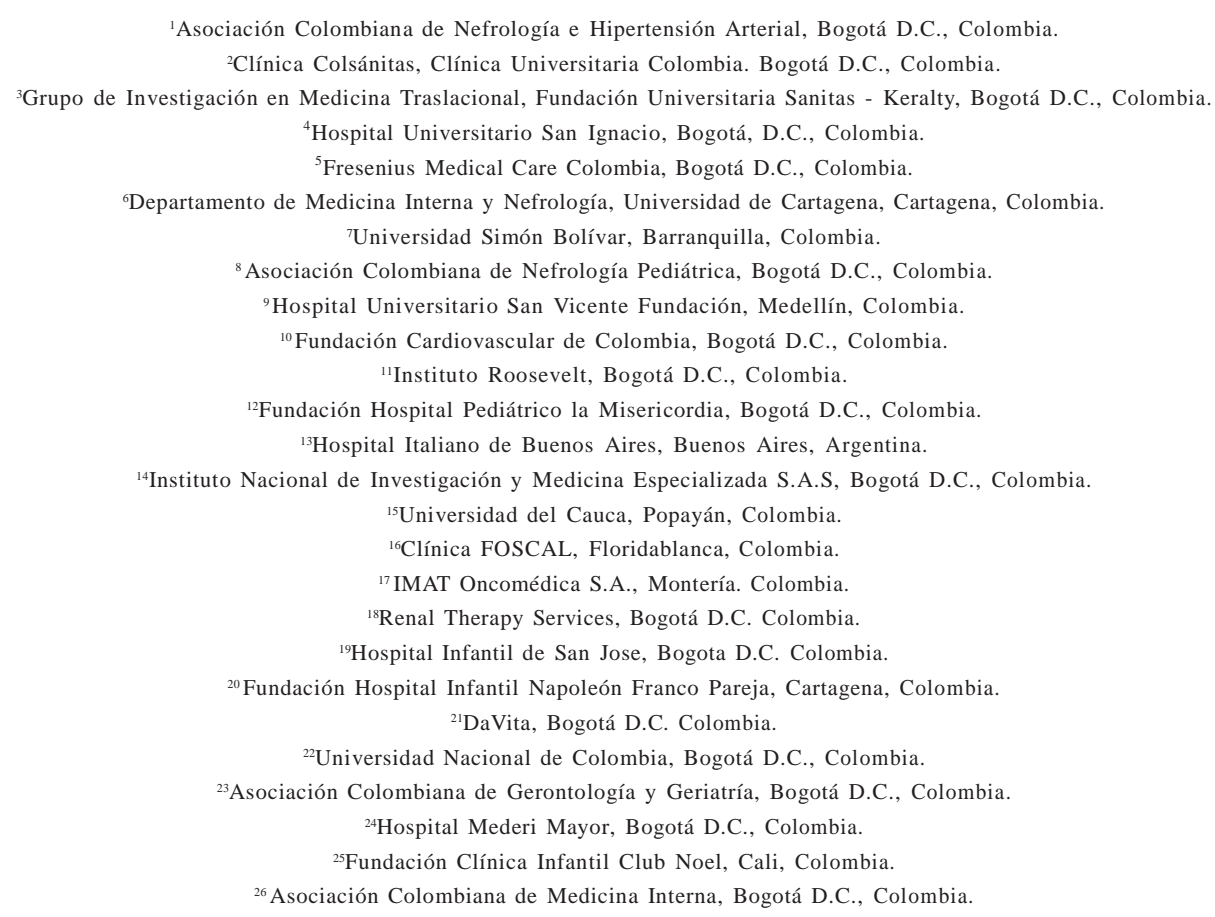

Citación: González C, Yama E, Yomayusa M, Vargas J, Rico J, Ariza A, et al. Consenso colombiano de expertos sobre recomendaciones informadas en la evidencia para la prevención, el diagnóstico y el manejo de la lesión renal aguda por SARS-CoV-2/COVID-19. Rev. Colomb. Nefrol. 2020;7(Supl. 2):89-117, https://dx.doi.org/ 10.22265/acnef.7.Supl.2.473

Correspondencia: Camilo González, camilo.gonzalez@javeriana.edu.co

Recibido: 02.06 .20 - Aceptado: $02.06 .20 \cdot$ Publicado en línea: 02.06.20 


\begin{abstract}
Resumen
Introducción: la lesión renal aguda es una complicación frecuente en pacientes con COVID-19 y su aparición es un potencial indicador de disfunción multiorgánica y de gravedad de la enfermedad.

Objetivo: desarrollar, mediante un consenso de expertos, recomendaciones para la prevención, el diagnóstico y el manejo de la lesión renal aguda en pacientes con infección por SARS-CoV-2/COVID-19 con base en la evidencia disponible.

Materiales y métodos: a partir de una rápida revisión sistemática en las bases de datos EMBASE y PubMed y en los portales de algunas sociedades científicas, se formularon recomendaciones preliminares, las cuales fueron consultadas a un colectivo experto a través de una herramienta en línea. Se definió acuerdo respecto a las recomendaciones cuando se obtuvo aprobación en al menos el $70 \%$. La calidad de la evidencia se evalúo de acuerdo con el tipo de documento incluido y la fuerza de las recomendaciones se clasificó como fuerte o débil.

Resultados: la consulta al colectivo de expertos tuvo lugar entre el 24 y 29 de mayo de 2020 . El rango de acuerdo osciló entre 75,5 \% y $100 \%$ y 50 expertos clínicos declararon su conflicto de interés. Se lograron establecer recomendaciones para prevenir, diagnosticar y manejar la lesión renal aguda en pacientes con infección por SARS CoV2/COVID-19.

Conclusiones: aunque la información disponible de buena calidad respecto a lesión renal aguda en paciente con COVID-19 es escasa, las recomendaciones aquí presentadas permitirán orientar la toma de decisiones clínicas y estratégicas alrededor de pacientes con esta complicación; de igual forma se garantizará un cuidado centrado en las personas y con altos estándares de calidad, y la generación de políticas de seguridad, salud y bienestar para los equipos multidisciplinarios de atención.
\end{abstract}

Palabras clave: SARS-CoV-2, COVID-19, lesión renal aguda (DeCS).

doi: https://doi.org/10.22265/acnef.7.Supl.2.473

\begin{abstract}
Introduction: Acute kidney injury is a frequent complication in patients with COVID-19 and its occurrence is a potential indicator of multi-organ dysfunction and disease severity.

Objective: Develop, through an expert consensus, evidence-based recommendations for the prevention, diagnosis, and management of acute kidney injury in patients with SARS CoV2 / COVID-19 infection.

Materials and methods: Based on a rapid systematic review in Embase and Pubmed databases and documents from scientific societies, we made preliminary recommendations and consulted with an expert group through an online tool. Then we defined agreement after at least $70 \%$ consensus approval. Quality evidence was evaluated according to the type of document included. The strength of the recommendations was graded as strong or weak.

Results: Fifty clinical experts declared their conflict of interest; the consultation took place between May 24 and 29, 2020. The range of agreement ranged from $75.5 \%$ to $100 \%$. Recommendations for prevention, diagnosis and management of acute kidney injury in patients with SARS CoV2 infection are presented.

Conclusions: Although the good quality information available regarding acute kidney injury in patients with COVID-19 is scarce, the recommendations of clinical experts will guide clinical decision-making and strategies around patients with this complication, guaranteeing care focused on the people, with high quality standards, and the generation of safety, health and wellness policies for multidisciplinary care teams.
\end{abstract}

Keywords: SARS-CoV-2, COVID-19, acute kidney injury (MeSH).

doi: https://doi.org/10.22265/acnef.7.Supl.2.473

\section{Introducción}

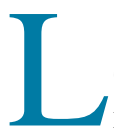

a lesión renal aguda (LRA) es una condición que ha tomado gran relevancia durante la pandemia por SARS-CoV-2, pues se ha descrito como una complicación frecuente en pacientes con COVID-19, además su aparición es un potencial indicador de disfunción multiorgánica y gravedad de la enfermedad ${ }^{1}$. Algunos resultados de imágenes y autopsias revelan diferentes mecanismos de lesión renal en pacientes con COVID-19, entre los cuales se encuentran la infiltración viral renal cuando su manifestación es en fase precoz y como parte de la disfunción multiorgánica en casos tardíos del curso de la enfermedad ${ }^{2,3}$.
Dado este panorama, es entonces un compromiso de la Asociación Colombiana de Nefrología e Hipertensión Arterial y la Asociación Colombiana de Nefrología Pediátrica generar recomendaciones basadas en evidencia para orientar la toma de aquellas decisiones clínicas que impacten los desenlaces y los resultados globales, pues se sabe que el reconocimiento temprano del compromiso renal en pacientes con COVID-19 y el uso de medidas preventivas y terapéuticas para limitar la progresión a etapas más graves son medidas cruciales para reducir la morbimortalidad.

El presente artículo hace parte de la serie de recomendaciones generadas por el consenso colom- 
biano de expertos para orientar la toma de decisiones en la prevención, el diagnóstico y el manejo de infección por SARS CoV2 o COVID-19 con enfermedad renal crónica y se centra en el tratamiento de la LRA.

\section{Materiales y métodos}

La búsqueda de la evidencia se basó en la LRA asociada a COVID-19. El presente artículo se organizó por secciones y en cada una se presentaron temas que se abordaron a través de una revisión rápida de literatura hecha en las bases de datos PubMed y EMBASE y en los sitios oficiales de desarrolladores de guías de práctica clínica (GPC) y de algunas sociedades científicas .

La estrategia de búsqueda se estableció utilizando los términos MeSH, Emtree o texto libre, según la fuente consultada, y usando conectores boléanos AND y OR. Los términos de búsqueda empleados fueron: "acute kidney disease", "acute kidney injure", "acute renal failure", "Sars Cov 2", "COVID-19", "acute peritoneal dialysis", "cytokine storm" y "cytokine clearance".

Se incluyeron GPC, comunicados, reportes técnicos, revisiones sistemáticas, ensayos clínicos, estudios observacionales, series de casos y reportes de casos, según su pertinencia para cada tema.

La calidad de los estudios incluidos se midió mediante la coordinación metodológica aplicando las herramientas AGREE II para guías de práctica clínica, AMSTAR-2 para revisiones sistemáticas y meta-análisis, RoB para ensayos clínicos, New Castle Otawa para estudios observacionales (cohortes o casos y controles) y Joanna Briggs Institute para series de casos o reportes de caso. Los resultados de la búsqueda se presentan en el Anexo A.

El colectivo de expertos fue consultado entre el 24 y el 29 de mayo de 2020, a través de una herramienta en línea, acerca de su posición (acuerdo, desacuerdo) frente a cada recomendación preliminar; cada participante tuvo la oportunidad de pre- sentar observaciones y justificar el desacuerdo. A partir de los resultados, para cada recomendación se estimó el porcentaje de acuerdo, siendo el numerador el número de personas que expresaron esta postura y el denominador, el total de personas que respondieron a dicha recomendación. Se definió acuerdo para la recomendación cuando se obtuvo $70 \%$ o más de aprobación por parte de los respondedores de la herramienta. Para las recomendaciones que no alcanzarán acuerdo se planeó discutirlas en una sesión de consenso; sin embargo, todas las recomendaciones preliminares divulgadas y consultadas superaron el umbral y no hubo necesidad de pasar a sesión virtual de consenso. Los resultados se presentan en Anexo B.

La calidad de la evidencia se evaluó de acuerdo con el tipo de documento incluido y la fuerza de las recomendaciones se clasificó como fuerte o débil.

\section{Mecanismos fisiopatológicos}

Las causas de la LRA asociadas a COVID-19 se encuentran en estudio; sin embargo, y a pesar de la reciente aparición de la enfermedad, ya existen algunas postulaciones al respecto.

Ronco \& Reis ${ }^{1}$ proponen que la LRA por SARSCoV-2 se da a través de tres vías: síndrome de liberación de citocinas, comunicación orgánica bidireccional y compromiso sistémico:

En la primera vía, el daño por tormenta de citoquinas o síndrome de liberación de citoquinas está mediado principalmente por la Interleucina-6 (IL-6) proinflamatoria, aunada a la secreción del factor de crecimiento vascular endotelial, la proteína quimioatrayente de monocitos - 1 y la Interleucina- 8 (IL-8), así como a la reducción en la expresión de E-cadherina en células endoteliales, lo cual está asociado a un aumento de la permeabilidad vascular como marco fisiopatológico de la hipotensión y la disfunción pulmonar en el síndrome de dificultad respiratoria aguda (SDRA, por su sigla en inglés) ${ }^{4}$. Otros factores asociados a la liberación de citocinas incluyen la oxigenación por membrana extracorpórea (ECMO), la ventilación mecánica invasiva y la te- 
rapia de reemplazo renal continuo. En pacientes con evidencia de tormenta de citocinas puede presentarse LRA como consecuencia de lesiones endoteliales sistémicas, inflamación intrarrenal, aumento de la permeabilidad vascular, depleción de volumen y cardiomiopatía, lo que puede conducir al síndrome cardiorenal tipo 1 , el cual se manifiesta con edemas, derrames pleurales, generación de tercer espacio con hipertensión abdominal e hipotensión.

La segunda vía está mediada por la estrecha relación entre el daño alveolar, miocárdico y tubular. La miocarditis por síndrome de liberación de citocinas y la miocarditis viral aguda pueden contribuir a la congestión de la vena renal, la hipotensión y la hipoperfusión renal, lo que lleva a una reducción en la tasa de filtración glomerular. De igual manera, la hiperinflamación y sobreproducción de citoquinas está involucrada en el daño bidireccional pulmón-riñón y el epitelio tubular renal lesionado promueve la regulación positiva y el aumento de la concentración de IL-6, lo que se asocia con una mayor permeabilidad alveolo-capilar y con hemorragia pulmonar. El mecanismo directo de la lesión de la IL-6 a las células epiteliales y endoteliales del pulmón aún no se ha explorado. Asimismo, el SDRA puede causar hipoxia medular renal, que es un daño adicional a las células tubulares.

La tercera vía está mediada por el efecto sistémico de varios factores como balance positivo de líquidos, lesión endotelial, hipotensión y pérdida de líquidos en tercer espacio, rabdomiolisis y endotoxinas.

En resumen, los mecanismos de lesión renal resultante de estas vías incluyen lesión directa de citoquinas, síndrome cardiorenal tipo I, hipoxia medular renal, síndrome compartimental renal, toxicidad tubular, hipoperfusión renal y LRA séptica ${ }^{1}$.

La edad avanzada, la mayor gravedad de la enfermedad, la diabetes mellitus y el balance positivo de líquidos son factores de riesgo independientes para el desarrollo de LRA, pero además en su gravedad influyen edad avanzada, índice de masa corporal alto, diabetes mellitus, antecedentes de insuficiencia cardíaca, presión máxima en las vías respiratorias y compromiso multiorgánico ${ }^{5}$.
Reportes de autopsia sugieren lesión endotelial con depósito de partículas virales en el tejido pulmonar y renal, lo cual puede indicar una cuarta vía de lesión y que la viremia es una posible causa de daño endotelial renal y un probable factor determinante de la LRA ${ }^{6}$. Su et al. ${ }^{7}$ reportaron la presencia de partículas similares a virus en podocitos y células epiteliales tubulares renales mediante microscopía electrónica y tinción de anticuerpo de nucleoproteína SARS positiva; sin embargo, no existe evidencia suficiente de la presencia de ARN del SARS-CoV-2 en el tejido renal. Estos resultados indican que el SARS-CoV-2 podría infectar directamente los túbulos renales humanos e inducir inclusiones tubulares renales citoplasmáticas, una característica observada en otras nefropatías asociadas a virus ${ }^{7}$.

Por otro lado, existe evidencia de que el SARSCoV-2 puede infectar directamente el epitelio tubular renal proximal y los podocitos a través de una quinta vía dependiente de la enzima convertidora de angiotensina 2 (ECA-2) teniendo en cuenta que su expresión es más común en el tejido renal, además de la regulación positiva del receptor ECA-2 y el SARS-CoV-2, lo que genera disfunción mitocondrial, necrosis tubular aguda, formación de vacuolas de reabsorción de proteínas y glomerulopatía colapsante cuyo epifenómeno final es la proteinuria, incluso presente de manera temprana ${ }^{4-6,8}$.

La sexta vía de lesión renal involucra la inmunidad innata y las vías de coagulación. En esta la activación de macrófagos asociada a COVID-19, el aumento de los niveles de ferritina, la tormenta de citoquinas y la liberación de patrones moleculares asociados a patógenos y proteínas moleculares relacionados a daños pueden liberar el factor tisular y la activar factores de coagulación que crean una predisposición a la hipercoagulabilidad ${ }^{9}$.

Por otro lado, reportes clínicos y de autopsias de pacientes con COVID-19 atendidos en China y Estados Unidos confirman la presencia de la coagulación intravascular diseminada con trombosis de vasos pequeños e infarto pulmonar, e incluso muestran evidencia de microangiopatía con infarto esplénico y renal asociado a elevación de dímero $\mathrm{D}$ y trombocitopenia, los cuales se correlacionan con peores re- 
sultados ${ }^{10}$. Existen, igualmente, reportes de mayor incidencia de coagulación de circuitos en pacientes con COVID-19 sometidos a diálisis y aumento de lesión miocárdica que imita el infarto del miocardio, posiblemente por miocarditis y microangiopatía, por lo tanto es probable que el estado hipercoagulable que se observa en los casos graves podría asociarse a necrosis tubular aguda o necrosis cortical y, por lo tanto, insuficiencia renal irreversible ${ }^{11}$.

La inmunidad innata y las vías de coagulación están estrechamente relacionadas. La activación de macrófagos asociada a COVID-19, la hiperferritinemia, la tormenta de citoquinas y la liberación de patrones moleculares asociados a patógenos y proteínas moleculares relacionadas a daños pueden provocar la liberación del factor tisular y la activación de factores de coagulación que crean una predisposición a la hipercoagulabilidad. El SARS-CoV-2 también puede atacar a los linfocitos, ya que expresan la ECA-2, lo que conduce a la activación de los linfocitos y, en consecuencia, a la muerte celular inducida por la activación que puede provocar linfopenia de las células T CD4+ y CD8+. Además, las vías de procoagulación y los sistemas complementarios pueden activarse entre sí.

Diao et al. ${ }^{12}$ observaron una fuerte deposición del complemento C5b-9 (complejo de ataque de membrana) en túbulos renales de seis pacientes con infección por SARS-CoV-2, lo que sugiere la activación de la vía del complemento. Una interacción entre la hiperactividad de la angiotensina II (AngII), las vías inmunitarias innatas/adaptativas y del complemento y el sistema de coagulación podría influir en la gravedad y los resultados del AKI . La agregación de eritrocitos inducida por inflamación (reflejada como una velocidad de sedimentación globular elevada) y la patología mediada por el hemo pueden empeorar el estrés oxidativo, la inflamación y la activación del complemento y agravar la lesión microvascular. Además, la diafonía de órganos entre el pulmón lesionado, el corazón y el riñón puede empeorar la patología. Se requieren entonces estudios detallados para descifrar la naturaleza de la disfunción de la coagulación, la microangiopatía y el papel potencial de las vías inmunitarias y del complemento innatas para obtener más información sobre la patología renal en COVID-19.
La vigilancia estricta, la prevención y la evaluación integral y multidisciplinaria de las personas con COVID-19 son estándares de calidad en el contexto de un programa de gestión clínica nefrológica y por tanto deben ser un imperativo en la atención de estos pacientes a fin de prevenir complicaciones y proteger la función renal en estadios tempranos de la enfermedad ${ }^{13,14}$, además su implementación permite la gestión de recursos durante la pandemia, en virtud que la LRA continua siendo la consulta hospitalaria más común para los nefrólogos, tal como lo sugirieron Faubel \& Edelsteinse ${ }^{15}$ en 2015. De igual forma se debe tener en cuenta que el personal de salud asignado al cuidado de pacientes en terapia de soporte renal (TSR) está altamente capacitado, pero es escaso y con baja posibilidad de ser reemplazado ${ }^{16}$.

Por ende, se enfatiza en la importancia de hacer una detección y reanimación temprana y de prevenir a través del control en el uso de nefrotoxinas, el monitoreo hemodinámico, el gasto urinario, el control de creatinina sérica y otros biomarcadores de pronostico en pacientes con sospecha o diagnóstico de COVID-19 ${ }^{1,17}$.

En los pacientes críticos es fundamental mitigar el volutrauma y el barotrauma mediante la ventilación con protección pulmonar para reducir el riesgo de LRA al limitar los efectos hemodinámicos inducidos por la ventilación y la carga de citocinas en el riñón ${ }^{18}$.

\section{Contexto epidemiológico}

La frecuencia de la LRA en pacientes con COVID19 es variable según los reportes publicados a la fecha, además es probable que la carga general de LRA en COVID-19 se subestime, ya que los valores de creatinina al ingreso podrían no reflejar la verdadera función renal previa al ingreso dado que los valores de creatinina sérica basales podrían no estar disponibles en la evaluación inicial ${ }^{2}$. Sin embargo, se puede considerar como una complicación común que ocurre entre el $0,5 \%$ y el $75,4 \%$ de los pacientes ${ }^{2,3,19}$ y entre el $7^{\circ}$ y $15^{\circ}$ día del inicio de la enfermedad ${ }^{20}$, siendo las comorbilidades más frecuentes las enfermedades cardiovasculares, la enfermedad renal crónica, la dia- 
betes y la hipertensión arterial ${ }^{3,21}$. La LRA puede afectar aproximadamente al 20-40\% de los pacientes ingresados a la unidad de cuidados intensivos (UCI) ${ }^{22}$ y se considera un marcador de gravedad de la enfermedad y un factor pronóstico negativo para la supervivencia ${ }^{11}$. Además, se reporta que cerca del $20 \%$ de los pacientes con COVID-19 ingresados a la UCI requieren terapia de reemplazo renal en una mediana de 15 días desde el inicio de la enfermedad.

Los reportes de LRA disponibles en el marco de la pandemia incluyen aumento de creatinina en el $19 \%$ de los casos, curso con proteinuria el $89 \%$, aumento de nitrógeno úrico (BUN) en el $31 \%$, albuminuria en el $34 \%$ y proteinuria y hematuria en el $44 \%^{2,3,13}$. Además, se han reportado dos casos de glomerulopatía colapsante entre pacientes con COVID-1921.

Hirsch et $a l .{ }^{23}$, en un estudio observacional de 5.449 pacientes con COVID-19 de Nueva York, Estados Unidos, reportaron que al $37 \%$ de los casos se le diagnosticó LRA, de los cuales el $47 \%$ correspondía a LRA leve, $22 \%$ a moderada y $31 \%$ a severa. En ese estudio también se observó hematuria y proteinuria en $46 \%$ y $42 \%$, respectivamente. Además, el $15 \%$ de los pacientes requirieron diálisis y el $97 \%$ de estos fueron sometidos a ventilación mecánica. Los predictores independientes de LRA incluyeron edad avanzada, raza negra, diabetes, hipertensión, enfermedad cardiovascular, ventilación mecánica y uso de medicamentos vasopresores ${ }^{23}$.

Los pacientes con COVID-19 que presentan LRA a menudo requieren soporte renal ${ }^{24}$. La TSR es requerida entre el $1 \%$ y el $9 \%$ de los pacientes hospitalizados y hasta en el $40 \%$ de pacientes en
$\mathrm{UCI}^{25-27}$. Por su parte, la terapia de remplazo renal continua (TRRC) es usada entre el $0,8 \%$ y el $61 \%$ de los pacientes críticos ${ }^{3,20,21}$.

La tasa de mortalidad en pacientes con COVID19 y LRA puede ser hasta del $30 \%{ }^{26}$, y aunque al menos el $67 \%$ de estos recupera completamente la función renal, el $19 \%$ continua con requerimientos de hemodiálisis luego del alta hospitalaria ${ }^{28}$.

Las cifras reportadas tienen una gran variabilidad, lo cual puede deberse a que existen diferentes definiciones de LRA, a que se hacen reportes para diferentes poblaciones (hospitalizados y pacientes en UCI) y a que los tiempos de reporte en el curso de la pandemia pueden ser distintos ${ }^{20,29}$. Una de las definiciones empleadas se basa en los criterios establecidos por el consorcio KDIGO (Tabla 1) e indica que la LRA corresponde al aumento de la creatinina sérica por encima de $0,3 \mathrm{mg} / \mathrm{dL}$ en 48 horas o a un aumento de este compuesto de más del $30 \%{ }^{30}$; otra postura incluye, además, el aumento >1,5 veces el valor inicial de este marcador (valor estimado de los siete días previos) o un volumen de orina $<0,5 \mathrm{~mL} / \mathrm{kg} / \mathrm{hora}$ durante 6 horas $^{13}$. En el mismo sentido, Pei et al. ${ }^{2}$ indican que los criterios ampliados en el diagnóstico de LRA aumentan la frecuencia de esta condición; la definición de estos autores también incluye aumento o disminución de los niveles de creatinina sérica en un $50 \%$ durante la estancia hospitalaria (utilizando los niveles registrados al ingreso como referencia), con o sin oliguria ${ }^{2}$.

\section{Recomendaciones generales}

- Se sugiere emplear la definición de lesión renal aguda como el aumento de la creatinina sérica

Tabla 1. Clasificación del consorcio KDIGO para lesión renal aguda.

\begin{tabular}{|c|l|l|}
\hline Estadio & \multicolumn{1}{|c|}{ Criterio con creatinina sérica } & \multicolumn{1}{|c|}{ Diuresis en gasto urinario } \\
\hline 1 & $\begin{array}{l}\text { Incremento } \geq 0,3 \mathrm{mg} / \mathrm{dL} \text { en } 48 \text { horas o 1,5-1,9 veces } \\
\text { respecto al valor de base en los últimos 7 días }\end{array}$ & $<0,5 \mathrm{~mL} / \mathrm{kg} / \mathrm{hora}$ durante 6-12 horas \\
\hline 2 & Incremento 2-2,9 veces el basal & $<0,5 \mathrm{~mL} / \mathrm{kg} / \mathrm{h}$ por 12 o más horas \\
\hline 3 & $\begin{array}{l}\text { Incremento } \geq 3 \text { veces el basal o } \geq 4 \mathrm{mg} / \mathrm{dL} \mathrm{o} \\
\text { necesidad de terapia de soporte renal }\end{array}$ & $\begin{array}{l}<0,3 \mathrm{~mL} / \mathrm{kg} / \mathrm{h} \text { por } 24 \text { o más horas o anuria } \\
\text { por } 12 \mathrm{o} \text { más horas. }\end{array}$ \\
\hline
\end{tabular}

Fuente: Elaboración propia.

94 Consenso colombiano de expertos sobre recomendaciones informadas en la evidencia para la prevención... 
por encima de $>0.3 \mathrm{mg} / \mathrm{dL}$ en 48 horas a pesar de adecuada reanimación o un aumento de más del $50 \%$ respecto al valor de base en los últimos 7 días o volumen de orina menor a $0.5 \mathrm{ml} / \mathrm{kg}$ / hora durante 6 horas, según las guías vigentes de KDIGO. (Fuerte a favor)

- Se recomienda clasificar la severidad de la LRA asociada a COVID-19 según la recomendación vigente del consorcio KDIGO (Fuerte a favor ).

\section{Factores de riesgo y pronóstico}

La LRA es multifactorial en pacientes con cuadro grave de infección por SARS-CoV-2 ${ }^{16}$. Además, la edad; la presencia de comorbilidades como hipertensión, diabetes, enfermedad coronaria, enfermedad renal crónica, hipovolemia y manifestaciones de choque séptico, y el uso de medicamentos nefrotóxicos son reportados como factores de riesgo en esta población ${ }^{12,20,26,31}$. De igual forma, es importante mencionar que un número importante de pacientes con COVID-19 requieren ventilación mecánica, la cual se asocia con el desarrollo de LRA ${ }^{12}$.

En general, los resultados de pacientes con LRA asociada a COVID-19 son variables, pues este tipo de lesión se puede considerar incluso, en sí misma, un factor pronóstico de mortalidad en pacientes hospitalizados ${ }^{26}$. La gravedad de la LRA se asocia positivamente con edad avanzada, índice de masa corporal alto, diabetes mellitus, antecedentes de insuficiencia cardíaca, mayor presión máxima en las vías respiratorias y mayor evaluación secuencial de insuficiencia orgánica.

Li et al. ${ }^{13}$ reportaron que la LRA aumenta el riesgo de mortalidad por COVID-19 5,3 veces respecto a los que no desarrollan este tipo de lesión, lo que coincide con otras investigaciones ${ }^{25}$ donde se han reportado desenlaces semejantes para pacientes ingresados en UCI que cursan con LRA dependiente de diálisis.

La proteinuria y el aumento de los niveles de creatinina sérica son marcadores comunes entre pacientes con LRA y COVID-19 que tienen desenla- ce fatal, por lo que se podrían considerar dentro de los factores asociados a mortalidad ${ }^{13,19,21}$. La hipercalemia, la acidemia y la sobrecarga de fluidos también han sido relacionados con la muerte en estos pacientes ${ }^{25}$.

Yang et $a l .{ }^{21}$, en un estudio de cohorte retrospectiva, encontraron que la TRRC reduce el riesgo de morir en un $68 \%$ en pacientes ventilados respecto a aquellos que no reciben esta terapia (HR: 0,324, IC95 \%: 0,118-0,893). Estos autores además sugirieron que la modalidad, el momento de inicio y la intensidad de TSR, anticoagulación y manejo de acceso vascular son factores pronóstico en pacientes con COVID-19 y LRA ${ }^{21}$. Por su parte, Gebistorf et al. ${ }^{32}$ hallaron que el óxido nítrico inhalado durante el SDRA por causas diferentes a COVID-19 aumenta en un $59 \%$ el riesgo de desarrollar LRA (RR: 1,59; IC95 \%: 1,17-2,16).

\section{Recomendaciones}

- Se recomienda considerar como factores de riesgo de LRA asociada a COVID-19, la edad avanzada; comorbilidades como hipertensión, diabetes y enfermedad cardiovascular, requerimiento de ventilación mecánica, hipovolemia, choque, el uso de medicamentos nefrotóxicos, y e inhalación de óxido nítrico inhalado (Fuerte a favor).

- Se recomienda considerar la LRA como uno de los factores pronósticos de COVID-19. (Fuerte a favor).

- Se recomienda considerar como factores pronóstico de LRA en pacientes con COVID-19: a la necesidad de ventilación mecánica, de TSR, a los eventos de coagulación del sistema de soporte renal, la proteinuria, y la presencia de complicaciones complicaciones como hipercalemia, acidemia y sobrecarga de fluidos. (Fuerte a favor).

\section{Tratamiento}

Dada la alta probabilidad de que los pacientes con COVID-19 desarrollen LRA y debido a que el 
$9 \%$ de los casos en hospitalización y hasta $40 \%$ de los casos en UCI requieren $\mathrm{TSR}^{25-27}$, se han planteado algunas estrategias de manejo buscando prolongar el inicio de esta terapia, esto teniendo en cuenta que los recursos son limitados y que se presenta un aumento considerable de la demanda.

Según las experiencias reportadas por nefrólogos estadounidenses, la prevención o el retraso de hipercalemia a través de resinas de intercambio de potasio en pacientes con potasio sérico en aumento, la prescripción de diuréticos para mantener la euvolemia en pacientes no oligúricos, la evaluación del volumen intravascular por medio de ultrasonido, la creación de servicios de diálisis peritoneal aguda, la colocación de catéteres al lado de la cama de paciente no intubados y las estrategias restrictivas de reanimación hídrica son estrategias favorables en el manejo de la $\mathrm{LRS}^{12}$, lo cual es apoyado por distintos autores ${ }^{5,31}$.

El Brigham and Women's Hospital sugiere suspender los medicamentos nefrotóxicos y evitar el uso de antiinflamatorios no esteroideos, inhibidores de ECA, antagonistas de receptor de angiotensina y diuréticos, así como el uso de contraste yodado para imágenes en pacientes con LRA ${ }^{20}$. Por el contrario, Alberici et al. ${ }^{33}$ sugieren reconsiderar el bloqueo de sistema renina angiotensina en pacientes que cursan con deshidratación y posterior a un análisis de riesgo versus resultado clínico esperado debido a la escasez de evidencia que soporte que se deben suspender masivamente estos medicamentos ${ }^{33}$. Asimismo, Burgner et al.24 proponen el uso intensivo de diuréticos en pacientes con función renal residual como estrategia para la sobrecarga de volumen ${ }^{24}$.

\section{Recomendaciones}

- Se recomienda la optimización de volumen intravascular, para garantizar perfusión renal guiado por medidas convencionales de respuesta a volumen, según las recomendaciones vigentes y la disponibilidad en centro. (Fuerte a favor)

- Se sugiere que la reanimación con líquidos sea analizada de manera individualizada y evaluan- do riesgo-beneficio. Especialmente con fines de evitar sobrecarga de fluidos. (Fuerte a favor)

- Se recomienda evitar medicamentos nefrotóxicos como antiinflamatorios no esteroideos (AINEs), bloqueadores del eje renina angiotensina aldosterona, medios de contraste iodados, aminoglucósidos, vancomicina, entre otros, en la medida de lo posible. (Fuerte a favor)

- Se recomienda realizar evaluación y seguimiento estandarizado de función renal en pacientes hospitalizados con COVID-19, incluyendo control diario de creatinina en sangre y monitoreo de gasto urinario. (Fuerte a favor)

- Se recomienda el control estricto del balance de líquidos y monitoreo de electrolitos para mitigar la indicación de terapia de soporte renal anticipada, producto de complicaciones prevenibles o adquiridas por el manejo farmacológico. (Fuerte a favor)

- Se recomienda prevenir hipercalemia en pacientes con COVID-19, establecer las medidas farmacológicas vigentes oportunamente. (Fuerte a favor)

- Se recomienda en casos de falla respiratoria por SARS CoV-2 realizar ventilación mecánica protectora para mitigar baro y volutrauma, con sus repercusiones renales reconocidas. (Fuerte a favor)

- Se sugiere considerar el uso de diuréticos de asa para el manejo de balance de fluidos. (Fuerte a favor)

\section{Soporte renal}

Las indicaciones para iniciar TSR en paciente con LRA y COVID-19 no están claramente establecidas, y aunque existen diferentes posturas al respecto, los autores coinciden en recomendar este soporte solo para controlar o prevenir algunas complicaciones de la LRA como hipercalemia, sobre- 
carga de volumen y acidemia ${ }^{12,25,31}$. Además, se sugiere considerar manifestaciones urémicas, como encefalopatía urémica, pericarditis y oliguria, para el inicio de esta terapia ${ }^{34}$.

El momento indicado para dar inicio a la TSR y su dosificación deben determinarse en función de las características de cada paciente y las circunstancias clínicas ${ }^{18}$. La experiencia del BRIGHAM AND WOMEN HOSPITAL sugiere considerar las indicaciones habituales de diálisis, independientemente de la COVID-19, e indica que es el nefrólogo el encargado de determinar la necesidad, el momento y la modalidad del reemplazo renal según las circunstancias de cada paciente ${ }^{20,29}$.

Alberici et al..$^{33}$ aconsejan iniciar TRRC en pacientes con LRA que se encuentre en etapa 3 (definida como un aumento de 3 veces en los niveles de creatinina desde el inicio o creatinina $>4,0 \mathrm{mg} / \mathrm{dL}$ o definida según cantidad de diuresis: diuresis $<0,3 \mathrm{~mL} /$ $\mathrm{kg} / \mathrm{h}$ por $>24$ horas o anuria por $>12^{18,35}$. En caso de presentar sobrecarga de líquidos con insuficiencia respiratoria secundaria, se sugiere explorar el beneficio de diuréticos de asa teniendo en cuenta que estos no se deben usar ante sospecha de hipovolemia ${ }^{34}$.

Otra perspectiva sugiere que las indicaciones del tratamiento de TRRC deben basarse en indicaciones no renales, y que para prevenir y modular las tormentas de citoquinas se debe realizar una intervención temprana adecuada ${ }^{36}$.

\section{Recomendaciones}

- Se recomienda que el nefrólogo determine la necesidad, el momento y la modalidad del reemplazo renal evaluando cada paciente de manera aislada basado en los estándares de soporte renal vigente. (Fuerte a favor)

- Se recomienda considerar las indicaciones habituales de soporte renal para pacientes con COVID-19. (Fuerte a favor)

- Se recomienda el inicio de TSR en paciente con LRA con COVID-19 con complicaciones como hiperpotasemia, acidemia metabólica, sobrecarga de volumen y manifestaciones urémicas. (Fuerte a favor)

- Se sugiere iniciar TSR en pacientes COVID-19 con LRA estadio 3 según criterios KDIGO, considerando el contexto clínico más amplio: como la presencia de afecciones modificables con la terapia, y las tendencias de los laboratorios, más allá de un valor de creatinina o BUN. (Fuerte a favor)

\section{Modalidades de soporte renal}

Aunque la evidencia respecto a superioridad de la TSR en pacientes con LRA asociada a COVID19 es limitada, autores como Alles et al. ${ }^{16}$ sugieren suministrarla con base en la evidencia disponible, las condiciones del paciente y el contexto, siempre llevando a cabo las mejores prácticas. Si bien la elección de la modalidad y su dosificación está indicada por las características de cada paciente, en este raciocinio también juega un papel la experiencia del prescriptor y las modalidades disponibles (terapia de reemplazo renal continua e intermitente prolongada, hemodiálisis intermitente y diálisis peritoneal) ${ }^{28,37}$.

\section{Papel de las modalidades de soporte re- nal en pacientes con COVID-19 y LRA}

La TRRC es una modalidad que es frecuentemente usada en el manejo de pacientes con LRA durante la pandemia por COVID-19. Esta se basa en principios de difusión, convección, ultrafiltración y adsorción para filtrar la sangre y se recomienda en pacientes críticos, ya que permite el control de trastornos electrolíticos y acido-base, la eliminación de mediadores inflamatorios y la oxigenación en casos de sobrecarga de líquidos ${ }^{21}$. Algunos autores consideran que esta modalidad es una base de soporte multisistémico en pacientes críticos ${ }^{36}$.

Existe discusión frente a la dosis y la duración requerida durante la TRRC en pacientes con COVID19 y LRA: una postura recomienda restringirla a 10 horas y usar dosis aumentadas $(40-50 \mathrm{~mL} / \mathrm{kg} / \mathrm{h}) \mathrm{se}-$ 
gún la demanda de servicio ${ }^{37}$, y otra propone utilizar dosis de efluente de aproximadamente $20-25 \mathrm{~mL} / \mathrm{kg} /$ h y reducirlo hasta $15 \mathrm{~mL} / \mathrm{kg} / \mathrm{h}$ cuando se alcanza control metabólico ${ }^{34}$. Para instituciones que enfrentan escasez de líquido de reemplazo para TRRC esta última opción debería ser considerada entre los pacientes no hipercatabólicos ${ }^{29}$. Al respecto, la Asociación China de Medicina recomienda ajustar la dosis de TRRC de acuerdo con el objetivo del tratamiento: para mantener el equilibrio de volumen sugieren dosis de reemplazo $>20-25 \mathrm{~mL} / \mathrm{kg} / \mathrm{h}$ utilizando membranas biocompatibles y aplicando solución de reposición a base de bicarbonato. Esta entidad también sugiere que la tasa de excreción renal, el volumen de distribución aparente, la tasa de unión a proteínas plasmáticas y la tasa de filtración glomerular de los fármacos se debe evaluar exhaustivamente para determinar si la dosis de un fármaco se debe ajustar en pacientes con COVID-1936.

La terapia de reemplazo renal intermitente prolongada (TRRIP) incluye hemodiálisis extendida de baja eficiencia, hemodiafiltración sostenida de baja eficiencia, diálisis diaria extendida, diálisis continua lenta, diálisis lenta y hemofiltración venovenosa acelerada (AVVH) o hemodiafiltración intermitente prolongada ${ }^{38}$.

El centro de cuidado crítico EMORY en su guía de manejo de paciente crítico durante la pandemia, reporta preferencia en el uso de modalidades TRRC sobre la hemodiálisis intermitente (HDI) debido a que las primeras generan menor inestabilidad hemodinámica, proporcionan una eliminación superior del líquido y solucionan la sobrecarga de líquidos. Además, la HDI supone menor cantidad de recursos en personal de salud especializado ${ }^{25}$ es muy útil en pacientes con ECMO que usan catéter venoso central ${ }^{24}$.

La TRRIP supone un beneficio adicional sobre la TRRC en términos de capacidad y de recursos, pues permite tratar de dos a tres pacientes con tratamientos de seis horas cada uno ${ }^{24,34}$, esto ha sido reportado en unidades renales de Nueva York que dosificaron terapias de entre 6 y 12 horas de duración y tasas de flujo de entre 40 y $50 \mathrm{~mL} / \mathrm{kg} / \mathrm{h}$ debido al desborde en necesidad de servicio ${ }^{12}$.
La HDI es una modalidad para la cual se ha reportado que cerca del $67 \%$ de las sesiones en pacientes críticos no son bien toleradas, por lo que en algunos casos se requiere cambiar a terapia continuas ${ }^{28}$. Además, requiere personal de enfermería específico para su administración en relación 1:1 enfermera:paciente, suficiente suministro de agua y recursos de drenaje con altas presiones ${ }^{25}$. En caso de considerar esta modalidad se sugiere el uso de membranas de corte medio para mejorar la filtración de partículas proinflamatorias ${ }^{39}$.

Ante la escasez de máquinas de TRRC, la hemofiltración arteriovenosa se puede considerar en pacientes críticos, para la cual se requieren líneas arteriales y venosas centrales, además de vigilancia estricta del paciente y un registro que permita controlar el equilibrio de líquidos y electrolitos. Por exigencias técnicas y operativas esta modalidad debería ser considerada como último recurso ${ }^{24}$.

Otra alternativa de tratamiento es la hemodiálisis venosa continua con dilución previa y posterior a una dosis de $25 \mathrm{~mL} / \mathrm{kg} / \mathrm{h}^{35}$, especialmente cuando la fracción de filtración es una limitante en el mantenimiento del circuito funcional.

\section{Recomendaciones}

- Se recomienda que la decisión de inicio de la terapia de soporte renal (TSR) y la modalidad de elección sea discutida entre especialistas en cuidado intensivo, nefrología, enfermería y el paciente o familiares, teniendo en cuenta los recursos disponibles. (Fuerte a favor)

- Se sugiere que el equipo multidisciplinar formule las metas de la TSR diariamente, sin embargo, la responsabilidad de la dosificación de la modalidad es del nefrólogo. (Fuerte a favor)

- Se recomienda la terapia de reemplazo renal continua (TRRC) o terapia de reemplazo renal intermitente prolongada (TRRIP) como la modalidad de primera línea en el manejo de pacientes con LRA y COVID-19 críticamente enfermo, por su capacidad en mejor tasa de remoción de fluidos y mejor tolerancia hemodinámica. (Fuerte a favor) 
- En centros sin disponibilidad de TRRC o TRRIP o con baja experiencia con estos dispositivos, se recomienda proceder con la terapia disponible como hemodiálisis intermitente (HDI) o diálisis peritoneal (DP) como TSR en COVID-19. (Fuerte a favor)

- Se recomienda usar dosis aportada entre 20-25 $\mathrm{ml} / \mathrm{kg} / \mathrm{h}$ (prescrita $25-30 \mathrm{ml} / \mathrm{kg} / \mathrm{h}$ ) para la modalidad TRRC, los ajustes son dependientes del estado metabólico. (Fuerte a favor)

- Se sugiere usar la modalidad de hemodiafiltración veno venosa continua o hemodiálisis veno venosa continua más que la hemofiltración en caso de TRRC por LRA secundaria a COVID-19, con fines de disminuir la fracción de filtración y mejorar la durabilidad del circuito. (Fuerte a favor)

- En caso de aumento de demanda de diálisis y una capacidad reducida, se recomienda considerar la modalidad TRRIP, inclusive usando los dispositivos de TRRC para lograr un alcance de dos a tres pacientes por día por dispositivo. (Fuerte a favor)

- En caso de indicación de TRRIP, se recomienda usar una dosis mínima entre $40-80 \mathrm{ml} / \mathrm{kg} / \mathrm{h}$ y duración de la terapia entre 6 y 12 horas. (Fuerte a favor)

- Se sugiere que todo el personal de UCI esté capacitado para proporcionar TRRC a pacientes con LRA y COVID-19. (Fuerte a favor)

\section{Diálisis peritoneal}

Para responder al incremento de la demanda de diálisis en pacientes con COVID-19 y LRA, los nefrólogos de Nueva York crearon unidades de diálisis peritoneal aguda, lo cual es apoyado por otros autores quienes sugieren que esta opción debe recomendarse y estructurarse de manera urgente frente al riesgo de sobredemanda por la pandemia ${ }^{37}$.

No obstante, en general es escasa la información relacionada con diálisis peritoneal aguda y
COVID-19, por lo que surge la duda si la diálisis peritoneal aguda es una alternativa a la terapia de reemplazo renal en pacientes con LRA y COVID19. Además, no existe evidencia de superioridad de alguna de las modalidades de TSR respecto a la diálisis en este contexto, de hecho se han reportado desenlaces semejantes en términos de mortalidad, recuperación de función renal y complicaciones infecciosas ${ }^{29}$.

La diálisis peritoneal debe usarse con precauciones en pacientes con ventilación mecánica debido al incremento de presión intraabdominal y, por tanto, la restricción de la dinámica respiratoria. Sin embargo, ante la escasez de otras modalidades de tratamiento, la diálisis peritoneal se podría considerar, incluso en posición prono, la cual es un reto mayor $^{29}$.

Los intercambios manuales de dializado se inician inmediatamente después de la colocación del catéter utilizando recambios de 1 a 2 litros con intervalos de 2 o 3 horas, pero en la experiencia reportada no se ratifica la afectación sobre la ventilación ${ }^{12,27}$.

En síntesis, la diálisis peritoneal se presenta como una modalidad de soporte renal factible en el contexto de la pandemia por SARS-CoV-2 dado que requiere de menos recursos, incluyendo equipos, personal especializado e infraestructura ${ }^{29}$. De igual forma, esta modalidad permite reducir la carga de trabajo del personal de la salud, especialmente del personal involucrado en TSR y hemodiálisis ${ }^{27}$. No obstante, la diálisis peritoneal como modalidad de tratamiento en pacientes con LRA asociada a COVID-19 requiere algunas consideraciones para su aplicación correcta y segura como el uso de diálisis peritoneal automatizada con un ciclador, si está disponible, para reducir la exposición del personal de salud ${ }^{29}$.

\section{Recomendaciones}

- Se recomienda considerar la diálisis peritoneal aguda como modalidad alternativa de TSR en paciente con LRA y COVID-19, cuando no sea posible aplicar otra modalidad o para aliviar la 
carga de trabajo del personal encargado de hemodiálisis u otras modalidades. (Fuerte a favor)

- Se recomienda preferir el uso de diálisis peritoneal automatizada más que manual cuando sea posible, en pacientes con COVID-19. (Fuerte a favor)

- Se recomienda extremar medidas de bioseguridad durante los intercambios manuales de dializado. (Fuerte a favor)

\section{Terapias extracorpóreas para aclara- miento de citoquinas}

Si bien el contagio de SARS-CoV-2 requiere de respuesta inmune inmediata, procesos excesivos y descoordinados pueden tener implicaciones importantes en el curso de la enfermedad ${ }^{40}$. Una manifestación documentada del daño causado por citoquinas es el SDRA, en el cual se produce daño pulmonar por el incremento local y excesivo de citoquinas en el pulmón. Se estima que cerca de la tercera parte de los pacientes con COVID-19 presenta SDRA y que esta complicación se asocia con desenlaces fatales ${ }^{11}$. Además, se ha sugerido que la LRA puede ser consecuencia de la tormenta de citoquinas ${ }^{1}$.

Ante esta situación, el control de la tormenta de citoquinas es un imperativo la prevención de complicaciones en pacientes con presentaciones graves de COVID-19, para lo cual se ha implementado la supresión de la actividad inmune a través de inmunomoduladores; terapias anti-inflamatorias con corticoesteroides, inmunoglobulinas y antagonistas de interleuquinas (IL-1, IL-6); bloqueo del factor de necrosis tumoral, y terapias antivirales y extracorpóreas ${ }^{40,41}$.

Las terapias extracorpóreas son modalidades de tratamiento orientadas a eliminar los factores inflamatorios, aunque también se han reportado beneficios en la estabilización hemodinámica, la reducción de lactato y la prevención de daño de órganos en pacientes con COVID-19 severo ${ }^{35}$. Algunas de estas terapias son TRRC, intercambio plasmático, hemodiálisis intermitente y hemoperfusión ${ }^{38}$.

Expertos en purificación de sangre indican que la modalidad más usada en paciente con COVID-19 es la TRRC, cuyo beneficio radica en que mantiene el equilibrio del volumen, facilita una estabilidad hemodinámica, mejora la eficiencia del aclaramiento de toxinas de pequeño y mediano tamaño, mantiene la temperatura corporal y permite el soporte nutricional. El uso de esta modalidad implica tasa de flujo de efluente mínima entre 20 y $25 \mathrm{~mL} / \mathrm{kg} / \mathrm{h}$ cuando se realiza dilución posterior y entre 25 y $30 \mathrm{~mL} /$ $\mathrm{kg} / \mathrm{h}$ en casos de predilución. Si se considera filtración de sangre de alto volumen, los expertos sugieren usar tasas de flujo $>35 \mathrm{~mL} / \mathrm{kg} / \mathrm{h}$, mientras que en ultrafiltración lenta la tasa de remoción de volumen considerada es entre 2 y $5 \mathrm{~mL} / \mathrm{min}$, dependiendo del estado hemodinámico y del volumen del paciente ${ }^{36,42}$.

Por su parte, la adsorción de plasma, que se basa en materiales biocompatibles y con afinidad fisicoquímica para adsorber sustancias, ha tenido resultados prometedores en el tratamiento para la COVID-19. Otra modalidad que el consenso reporta con potencial beneficio en enfermedad por SARSCoV-2 es el intercambio de plasma que elimina toxinas de peso molecular bajo a grande, la cual tiene un potencial efecto en anomalías de coagulación ${ }^{36}$. Algunos expertos sugieren dosis de tratamiento de entre 1,5 y 2 veces el volumen plasmático del paciente con duraciones de entre $2 \mathrm{y}$ 4 horas usando tasas de flujo sanguíneo al inicio de entre 50 y $80 \mathrm{~mL} / \mathrm{min}$ y aumentando gradualmente hasta 100 o $150 \mathrm{~mL} / \mathrm{min}^{42}$.

La terapia de diafiltración de plasma (PDF, por sigla en inglés) consiste en eliminar las toxinas que se unen a las proteínas, las interleuquinas (IL-6, IL18) y otras moléculas inflamatorias mediante una membrana selectiva a través de una especie de hígado artificial, y tiene resultados comparables a la terapia de recambio plasmático y que en COVID19 han mostrado cierta eficacia. Expertos sugieren que la dosis de esta modalidad debe estimarse con base en el peso del paciente y el nivel de hematocrito, además recomiendan administrar al menos 2 litros de plasma cuando este componente es escaso ${ }^{36,42,43}$. 
La plasmaféresis puede ser útil en el tratamiento de la COVID-19 debido a la afinidad entre la envoltura viral y las lectinas; sin embargo, esta modalidad requiere mayor investigación ${ }^{44}$. Por otra parte, algunos autores sugieren que la hemoperfusión potenciada con un cartucho adsorbente de alta biocompatibilidad y resina microporosa (Cytosorb) tiene beneficios potenciales en esta enfermedad ${ }^{33,35}$, mientras que otros se oponen a su uso por falta de evidencia que la respalde ${ }^{29}$.

Para la optimización del filtrado algunos autores sugieren la combinación de modalidades: TRRC con modalidad de adsorción de plasma o de sangre, TRRC con hemofiltración, el uso de hemofiltración de alto volumen y anticoagulación efectiva ${ }^{35}$.

Dentro de las limitaciones reportadas para las terapias extracorpóreas se encuentran alto costo, dificultad de eliminación completa de moléculas inflamatorias en pacientes con COVID-19, riesgo de daño de células sanguíneas y eliminación de nutrientes, albúmina y medicamentos ${ }^{36,43,44}$.

Ante las limitaciones que se presentan con las terapias extracorpóreas para la eliminación de citoquinas, algunos autores sugieren extremar las medidas de monitorización de los signos vitales y las variables hemodinámicas; de igual forma se recomienda hacer seguimiento al volumen de líquido durante las terapias; al aclaramiento de solutos a través de medición de creatinina sérica, cuadro hemático (diario) y dosis de medicamentos potencialmente eliminados durante las terapias; a los electrolitos (cada 4 o 6 horas durante la terapia); al equilibrio acido-base; al índice de coagulación, y a las imágenes de tórax (al menos cada tercer día) en pacientes que reciben estas modalidades terapéuticas ${ }^{42}$.

\section{Recomendaciones}

- Se sugiere el uso de la modalidad de TRRC como primera línea de manejo indicado con terapias extracorpóreas en pacientes COVID-19 y LRA en presencia de síndrome por tormenta de citoquinas. (Fuerte a favor)

- No se recomienda el uso masivo de terapias de purificación sanguínea en infección por SARS-
CoV-2 severa, la evidencia en choque séptico es inconclusa. (Fuerte en contra)

- Se sugiere considerar el uso de terapias de purificación extracorpórea en pacientes graves con COVID-19, como terapia de eliminación de citoquinas en el síndrome por tormenta de citoquinas, cuando las terapias convencionales estén fallando o siendo insuficientes, y evaluando pronóstico individual del paciente. (Fuerte a favor)

- No se recomienda el uso de rutina de recambio plasmático terapéutico en COVID-19 severa, sin embargo, en centros con alta experiencia, puede ser usado cuidadosamente en casos específicos evaluando riesgo-beneficio y pronóstico individual. (Fuerte en contra)

- Se recomienda tener en cuenta la remoción de medicamentos por las distintas terapias y realizar ajustes correspondientes a la dosificación de los mismos, según las capacidades de aclaramiento esperadas o identificadas. (Fuerte a favor)

- Se recomienda control de electrolitos mínimo una vez por día durante la terapia, y más frecuente a criterio médico y cambios asociados con las distintas terapias. (Fuerte a favor)

- Se recomienda seguimiento de equilibrio acidobase e índice de coagulación más de una vez al día. (Fuerte a favor)

- Se recomienda seguimiento de imágenes de tórax al menos cada tercer día en pacientes que reciben estas modalidades terapéuticas. (Fuerte a favor)

\section{Criterios terapias extracorpóreas}

Las terapias extracorpóreas aquí analizadas tienen como principal objetivo la eliminación de citoquinas, pues las indicaciones de su uso en el contexto de la epidemia por SARS-CoV-2 no están claramente establecidas; sin embargo, hay información disponible de indicaciones renales y no renales 
para considerar el inicio de terapias extracorpóreas en paciente con COVID-19 severo $^{42}$.

\section{Indicaciones renales}

- LRA, particularmente estadio >2 que cumple con los criterios de la enfermedad clínica del riñón (KDIGO).

- Sobrecarga severa de líquidos y trastorno de equilibrio de electrolitos y ácido-base.

- Pacientes de hemodiálisis de mantenimiento con inestabilidad hemodinámica (en quienes se sugiere iniciar TRRC).

\section{Indicaciones no renales}

- SDRA grave, choque séptico, insuficiencia hepática aguda grave o síndrome de disfunción multiorgánica.

- Respuesta inflamatoria excesiva: concentración de mediadores inflamatorios del suero (como IL6) $>5$ veces el valor normal o tasa de aumento diario $>100 \%$.

- Fiebre alta refractaria a manejo (temperatura rectal $>39,5^{\circ} \mathrm{C}$ ).

La TRRC está indicada en pacientes con COVID-19 grave que cursan con sepsis y SDRA, y su inicio inmediato debe considerarse en pacientes con sobrecarga de volumen refractaria a diuréticos, hiperlactactemia severa $(>6,5 \mathrm{mmol} / \mathrm{L})$, aumento de potasio en sangre con cardiotoxicidad, acidosis metabólica severa $(\mathrm{pH}<7,1)$ y LRA estadio $>2$ con sepsis. De igual forma, se sugiere considerar tiempos de inactividad de TRRC en pacientes termodinámicamente estables, con destete de ventilación mecánica, con corrección de trastornos de equilibrios de electrolitos en agua y acido-base y con producción de orina sin diuréticos $>500 \mathrm{~mL}$ y con diuréticos $>1500 \mathrm{~mL}^{42}$.

Para la terapia de adsorción de plasma la información disponible sugiere que se inicie en la etapa temprana de la inflamación de la enfermedad por
SARS-CoV-2 o cuando el nivel de citoquinas proinflamatorias sea dominante ${ }^{36}$. De la misma manera, se recomienda considerar el inicio de terapia PDF en etapa temprana y media de la COVID-1943. Expertos han sugerido considerar tiempos de inactividad con modalidad de intercambio de plasma ante mejoría de síndrome de respuesta inflamatoria sistémica, función respiratoria e insuficiencia hepática aguda y disminución de niveles séricos de mediadores inflamatorios, al menos hasta el doble de valores normales ${ }^{42}$.

Debido al beneficio hemodinámico de las terapias extracorpóreas para eliminar citoquinas, se sugiere iniciar hemoperfusión en casos severos y complicados de COVID-19 que cursen con choque séptico e hiperlactactemia ${ }^{35}$.

Berhés et al. ${ }^{35}$ recomiendan el uso de adsorbentes como Cytosorb en casos de vasoplejía severa con hiperlactactemia y alto requerimiento vasopresor (noradrenalina $>0,3 \mu \mathrm{g} / \mathrm{kg} / \mathrm{min}$ ); en pacientes que no responden a terapia estándar para el choque séptico; ante la necesidad de TRRC o hemoperfusión; en pacientes con SDRA para inversión abdominal debido al deterioro de la oxigenación; como indicación para la terapia de reemplazo renal; como indicación de ECMO/ECLS, y para reducir la respuesta inflamatoria, el daño de las células endoteliales y la duración de la ventilación ${ }^{35}$. De igual forma, Alberici et $a l .{ }^{33}$ sugieren considerar este dispositivo en pacientes que no han sido tratados con tocilizumab y continuar su uso durante 24 horas después de iniciado el inmunomodulador o hasta finalizar el ciclo del dispositivo.

Vale la pena mencionar que a la fecha no se han reportado contraindicaciones para las terapias extracorpóreas en paciente COVID-19.

\section{Recomendaciones}

- Emplear como criterios para considerar las terapias de remoción de citoquinas en pacientes con COVID-19 grave: la presencia de LRA estadio >2 según criterios del consorcio KDIGO, SDRA severo, choque y manifestaciones de síndrome de tormenta por citoquinas como fiebre 
persistente, IL 6 elevada, hipoalbuminemia, ferritina elevada y proteína c-reactiva elevada (Fuerte a favor).

\section{Anticoagulación}

Se ha reportado que los pacientes con presentaciones graves de COVID-19 tienen alto riesgo de hipercoagulabilidad, con reducciones de $16 \%$ en el tiempo de tromboplastina parcial activada (aTTP) y de $30 \%$ en el tiempo de protrombina; además, poco más de un tercio de ellos cursan con incrementos de dímero- $\mathrm{D}^{42}$.

El estado de hipercoagulabilidad de pacientes con COVID-19 genera coagulación del circuito de TRRC, por lo que se deben adoptar medidas que garanticen el estado de los circuitos hasta por 72 horas, para lo que el Centro de Cuidado crítico EMORY recomienda adoptar un protocolo estándar de citrato en caso de coagulo o falla del circuito, iniciar infusión de heparina en la máquina de TRRC a través del prefiltro, medir los niveles de heparina del paciente y realizar los ajustes según metas y suspensión de protocolo de citrato. En caso de falla del circuito se debe administrar directamente vía intravenosa inhibidor de trombina, preferiblemente argatroban o bivalirudin, ajustar los niveles de tiempo de protrombina y suspender la infusión de heparina ${ }^{25}$.

Respecto al manejo de la hipercoagulabilidad, la información disponible incluye tres opciones de anticoagulación: citrato, heparinización sistémica no fraccionada y tratamiento sin anticoagulante. Teniendo en cuenta el riesgo de acumulación de citrato en pacientes con disfunción hepática grave, se ha sugerido el seguimiento cada 12 horas de los niveles de calcio sistémico $(<2,5)$ y ácido láctico y de cambios en el pH arterial. Con el uso de la segunda opción de anticoagulación también se sugiere monitorización de aTTP y antitrombina III $^{3,35,39}$.

Ronco et al. ${ }^{17}$ sugieren reducir la concentración de calcio ionizado posterior al filtro a aproximadamente $0,25-0,35 \mathrm{mmol} / \mathrm{L}$ con dosis inicial de citrato de $3,5 \mathrm{mmol} / \mathrm{L}$ en sangre tratada. Para casos en los que se prescriba protocolo basado en la heparina de bajo peso molecular, los autores sugieren iniciar con una dosis de $3,5 \mathrm{mg} / \mathrm{h}$ y una actividad sistémica antifactor $\mathrm{Xa}$ de 0,25 a $0,35 \mathrm{UI} / \mathrm{ml}$, mientras que con heparina no fraccionada la dosis sugerida es de $10-15 \mathrm{Ul} / \mathrm{kg} / \mathrm{h}$ y tiempo de aTTP de 60-90 segun$\operatorname{dos}^{17}$. La estrategia de anticoagulación debe ser la considerada habitualmente, pues no se recomienda la incursión en nuevas estrategias ${ }^{34}$.

Algunos pacientes con COVID-19 grave desarrollan alcalosis metabólica, hipernatremia y diferentes grados de daño hepático, lo que puede limitar la aplicación de anticoagulación local con citrato en pacientes con esta condición y hace que la heparinización sea una opción viable.

Es importante analizar cada caso de manera independiente teniendo en cuenta el riesgo de sangrado o sangrado activo y así ajustar los protocolos de anticoagulación ${ }^{36}$. Además, en caso de usar heparina o citrato durante la TSR se debe manejar un flujo sanguíneo $>120 \mathrm{~mL} / \mathrm{min}$ para evitar coagulación del circuito (la anticoagulación con heparina o citrato se debe usar durante el procedimiento junto con un flujo sanguíneo $>120 \mathrm{~mL} / \mathrm{min}$ para evitar la coagulación prematura del circuito).

\section{Recomendaciones}

- Se recomienda emplear estrategias de anticoagulación durante los procedimientos de TSR en pacientes con COVID-19, con el objetivo de prevenir la coagulación del circuito. (Fuerte a favor)

- Se recomienda usar el mecanismo de anticoagulación con el que el centro se encuentre más familiarizado, o con los requerimientos específicos del paciente cuando requiere anticoagulación sistémica. (Fuerte a favor)

- Se recomienda considerar el riesgo de sangrado o sangrado activo para la implementación de protocolos de anticoagulación. (Fuerte a favor)

- Se sugiere garantizar durante la TSR un flujo sanguíneo mayor a $120 \mathrm{ml} / \mathrm{min}$ para evitar coagulación del circuito, independientemente del pro- 
tocolo de anticoagulación implementado. (Fuerte a favor)

- Se sugiere usar protocolo de anticoagulación con citratos como estrategia de primera línea en la prevención de coagulación del circuito. (Debil A favor)

- Se recomienda considerar heparinización sistémica cuando falle el protocolo de citratos o cuando esta estrategia no está disponible. (Fuerte a favor)

- En el caso de implementar protocolo de citratos se recomienda realizar seguimiento estricto mínimo cada 12 horas de calcio iónico sistémico, del circuito, del calcio total del paciente y cambios en $\mathrm{pH}$ arterial. (Fuerte a favor)

- En el caso de implementar protocolo de heparina no fraccionada, se recomienda monitorización de aTTP para metas entre 60 y 90 segundos y según disponibilidad antitrombina III. Este último, especialmente si se denota coagulación temprana recurrente y no explicada de circuitos de TRRC o TRRIP. (Fuerte a favor)

- No se recomienda implementar protocolos de anticoagulación novedosos y diferentes a los de la práctica rutinaria durante la TSR. (Fuerte en contra)

\section{Acceso vascular}

Debido al requerimiento potencial de TSR en paciente con COVID-19, el acceso vascular debe ser priorizado dentro de las cirugías ${ }^{45}$. Su manejo se sugiere como factor pronóstico de COVID-19 en pacientes con $\mathrm{LRA}^{21}$.

La información disponible a la fecha indica que el procedimiento de implante de acceso vascular se debe realizar en un área específica cuando sea posible o en cama cuando el paciente se encuentra con ventilación mecánica. Varios autores coinciden en sugerir que este procedimiento lo debe realizar personal experto para evitar complicaciones y disminuir la exposición al SARS-CoV-2, y que además se debe usar una guía de ultrasonido y seguir las recomendaciones de bioseguridad ${ }^{3,36,42}$.

La efectividad de la TSR depende, entre otros factores, del acceso vascular, por lo que se requiere definir una vía de acceso y la longitud del catéter antes de realizar el procedimiento ${ }^{3}$ Para la definición de la vía de acceso vascular se debe tener en cuenta que la mayoría de los pacientes con COVID-19 requieren ventilación mecánica a través de traqueotomía o intubación endotraqueal y que por tanto en algunos casos esta modalidad terapéutica debe ser aplicada en posición prono, por lo que se debe garantizar el estado del acceso vascular ${ }^{36}$. La mayoría de los autores proponen la vena yugular interna derecha como primera opción; sin embargo, otros prefieren usar vías distantes de la vía aérea, como la vena femoral, para minimizar la exposición ${ }^{34,42}$.

Adams \& Mousa $^{46}$ evidencian en su estudio que el acceso venoso poplíteo fue implantado sin complicaciones en paciente con COVID-19 y permitió el inicio de TRRC inmediatamente. Estos autores resaltan que la vena poplítea es de fácil acceso, útil en pacientes que requieren ventilación en prono y segura para el personal de salud por la distancia entre la vía aérea del paciente y el lugar del procedimiento, lo que reduce las complicaciones como estenosis venosa central; sin embargo, es un acceso que requiere experticia por parte del cirujano, pues existe el riesgo de trombosis venosa profunda en extremidades inferiores y el catéter requerido es de mayor longitud ${ }^{46}$.

Todos los autores coinciden en reportar su oposición al uso de acceso subclavio; además, algunos sugieren evitar acceso por la vena yugular interna izquierda debido a la frecuencia de complicaciones y mala función ${ }^{36}$. El acceso vascular se debe manejar con precaución en paciente con requerimiento de TSR, aún más cuando no se pudo establecer un acceso adecuado ${ }^{32}$.

\section{Recomendaciones}

- Se recomienda que el implante de acceso vascular sea realizado por el equipo de salud con mayor experticia, para minimizar la exposición y riesgo de complicaciones. (Fuerte a favor) 
- Se recomienda que el procedimiento de colocación de catéter sea guiado por ultrasonido. (Fuerte a favor)

- Se recomienda que el personal de salud involucrado en este procedimiento siga las recomendaciones de bioseguridad y utilice EPP al menos nivel 2. (Fuerte a favor)

- Se recomienda realizar una planeación del acceso vascular de TSR considerando la necesidad de ventilación mecánica, la localización de dispositivos de invasión y requerimiento de posición prono en casos graves de COVID-19. (Fuerte a favor)

- Se recomienda que el acceso vascular sea implantado en la vena yugular interna derecha como primera opción. (Fuerte a favor)

- Se recomienda realizar control de radiografía de tórax después de implantar catéter yugular para TSR. (Fuerte a favor)

- En caso de ser necesario, se sugiere considerar como segunda opción de acceso vascular la vena femoral derecha teniendo en consideración los factores de riesgo para sobreinfección como la obesidad y la presencia de diarrea. (Fuerte a favor)

- Se recomienda evitar el acceso subclavio y yugular izquierdo. (Fuerte en contra)

- En pacientes con LRA por SARS-COV-2 y manejo con ECMO se recomienda establecer la conexión del dispositivo externo de soporte renal al circuido de oxigenación. Sin embargo, ante la evidencia o alta probabilidad de formación de coágulos en el circuito de ECMO, se recomienda establecer un acceso individual para la TSR. (Fuerte a favor)

\section{Bioseguridad}

Debido a la naturaleza de la COVID-19 y su mecanismo de transmisión, el seguimiento de medi- das de bioseguridad es imprescindible, sobre todo en ambientes hospitalarios y en UCI. Por tanto, a continuación se presentan algunas recomendaciones de bioseguridad en la prestación del soporte renal agudo que son de gran utilidad para evitar la diseminación hospitalaria de esta enfermedad durante la terapia de soporte renal.

Teniendo en cuenta la frecuencia de requerimiento de TSR para pacientes con LRA y COVID-19 a nivel hospitalario y UCI, algunos autores han sugerido que las máquinas se ubiquen fuera de la habitación de los pacientes para reducir el tiempo de exposición del personal de salud encargado de esta actividad y así gestionar mejor los EPP, y que los pacientes se ubiquen en habitaciones seguidas o salas aisladas para evitar su transporte y así optimizar el personal de salud ${ }^{12}$.

El personal de salud debe seguir las precauciones estándar, que incluyen lavado de manos en cinco momentos de la atención y uso racional y correcto de los EPP ${ }^{29}$.

Palevsky et al. ${ }^{29}$ sugieren que la máquina de TSR debe ser rotada cada 24 horas o cuando el circuito se coagule para minimizar el consumo de filtros y dispositivos adsorbentes. Asimismo, otros autores afirman que estas máquinas pueden ser usadas por diferentes pacientes una vez se realice el correspondiente proceso de desinfección y limpieza al finalizar cada tratamiento siguiendo protocolos habituales ${ }^{25,36,37}$.

Para el proceso de limpieza de superficie de las máquinas de TSR, las mesas de tratamiento y los elementos utilizados durante la terapia, se sugiere usar desinfectante a base de cloro una vez por turno; en casos de que no se encuentren contaminados con fluidos corporales se sugiere la limpieza y desinfección con soluciones con cloro $1000 \mathrm{mg} / \mathrm{L}$ que deben ser retiradas a los 30 minutos con agua limpia; en casos de contaminación visible se recomienda limpiar con material higroscópico y aplicar una solución con cloro de $2000 \mathrm{mg} / \mathrm{L}$ que debe ser retirada 30 minutos después con agua limpia ${ }^{25,36,37}$.

La información disponible sugiere incluir en los protocolos de bioseguridad el proceso de desecho 
del líquido residual de TRRC y el manejo y desecho de materiales utilizados durante las TSR, tales como tuberías, filtros y dispositivos de perfusión, los cuales se deben desechar y etiquetar de acuerdo con protocolos institucionales. En la etiqueta se sugiere especificar que se trata de desechos de pacientes con COVID-19, además se recomienda desinfectar con solución clorada de $1000 \mathrm{mg} / \mathrm{L}$ la bolsa que contiene los desechos ${ }^{36}$.

\section{Recomendaciones}

- Se recomienda seguir medidas universales de lavado de manos en cinco momentos de la atención y el uso racional y correcto de EPP. (Fuerte a favor)

- No se recomienda el uso de circuitos de sangre largos a pesar de que permitan ubicar las máquinas de TSR fuera de las habitaciones, como medida de prevención de contagio entre personal. (Fuerte en contra)

- Se recomienda aplicar TSR en pacientes COVID-19 en habitación o salas aisladas evitando el desplazamiento por la institución. (Fuerte a favor)

- Se recomienda continuar protocolos de limpieza y desinfección de las máquinas de TSR al finalizar los procedimientos. (Fuerte a favor)

- Se recomienda la limpieza y desinfección de la máquina de TSR, mesa de tratamiento y elementos utilizados durante la terapia, con solución clorada una vez por turno. (Fuerte a favor)

- Se recomienda seguir protocolos institucionales de desechos de material contaminado por COVID-19, y reforzar el etiquetado y desinfección de bolsas que contienen dicho material con solución clorada. (Fuerte a favor)

- Se recomienda realizar la disposición de líquidos de TSR siguiendo protocolo institucional y minimizando la generación de microgotas, gotas y aerosoles. (Fuerte a favor)

\section{Diálisis en pacientes con ERC estadio 5 críticamente enfermo}

No hay información clara de cuál es la forma indicada de realizar la TSR en pacientes con ERC estadio 5 dependiente de diálisis que ingresan en estado crítico por COVID-19 y la poca evidencia disponible no hace distinción entre estadios de la ERC. Por lo tanto, los expertos proponen las siguientes consideraciones para el manejo de este tipo de pacientes.

\section{Recomendaciones}

- Se recomienda dar continuidad al tratamiento de remplazo renal de base para ERC estadio 5 durante su estancia hospitalaria en cuidado crítico o sala general por COVID-19 en la habitación de aislamiento del paciente. (Fuerte a favor)

- Se recomienda dar continuidad a la diálisis peritoneal en pacientes con TSR por ERC 5, en la medida de lo posible. (Fuerte a favor)

- Se recomienda preferir diálisis peritoneal automatizada en pacientes bajo tratamiento de remplazo renal con diálisis peritoneal manual de base. (Fuerte a favor)

- Se recomienda evitar el uso de la fístula arteriovenosa como acceso para TRRC, o para TRRIP con tiempos de tratamiento superiores a 6 horas. (Fuerte a favor)

\section{Conclusión}

Este es el producto de las recomendaciones informadas en la pequeña evidencia existente de esta nueva enfermedad, validadas por un grupo de expertos activos en el manejo de pacientes con lesión renal aguda en Colombia. Tratándose de una nueva enfermedad, este documento puede ser objeto de actualizaciones parciales o completas, dependientes de la evidencia en curso. 


\section{Conflictos de interés y financiación}

Los expertos consultados debían declarar si tenían conflictos de interés mediante el diligenciamiento de un formato diseñado para este fin, a lo que 50 respondieron que sí tenían conflictos. Además el comité metodológico analizó el conflicto declarado y su potencial efecto en las respuestas emitidas para garantizar la transparencia del consenso.

El grupo desarrollador y participantes del consenso de expertos declararon el conflicto de interés a través de un formato en custodia el comité metodológico del consenso.

Adalberto Peña Wilches recibió recursos de Nikkiso de Colombia en 2020.

Alejandra Molano Triviño recibió recursos de Fundación cardioinfantil en 2016 y 2017.

David Ballesteros recibió recursos de AMGEN en 2014.

Freddy Ardila es accionista y empleado de RTS filial de Baxter.

Javier Galeano ha recibido recursos de Fresenius, Abbott, Abbvie.

Juan Guillermo Vargas ha recibido recursos de Alexion Colombia, Medtronic Colombia y Biomeriux Colombia.

Luis Alfonso Valderrama Cometa ha recibido recursos de Alexium y fue socio del Centro Médico Imbanaco, Cali.
María José Vargas Brochero ha recibido recursos de RTS.

Mercedes Alfaro Tejeda ha recibido recursos de Shire (2016), Novordisk (2019), Meak Sharp \& Dohme (2019).

Los demás autores declaran no tener conflicto de interés con la temática del consenso.

\section{Responsabilidades éticas}

\section{Protección de personas y animales}

Los autores declaran que para esta investigación no se han realizado experimentos en seres humanos ni animales.

\section{Confidencialidad de los datos}

Los autores declaran que han seguido los protocolos de su centro de trabajo sobre la publicación de datos de pacientes.

\section{Derecho a la privacidad $y$ consentimiento in- formado}

Los autores declaran que en este artículo no apa- recen datos de pacientes.

\section{Contribución de los autores}

Todos los autores participaron en la revisión de la literatura documentada por el metodólogo, participaron en la elaboración de las recomendaciones y todos realizaron la votación para validar la recomendación. 


\section{Referencias}

1. Ronco C, Reis T. Kidney involvement in COVID-19 and rationale for extracorporeal therapies. Nat Rev Nephrol. 2020;16(6):308-10http://dx.doi.org/10.1038/s41581-020-0284-7.

2. Pei G, Zhang Z, Peng J, Liu L, Zhang C, Yu C, et al. Renal Involvement and Early Prognosis in Patients with COVID-19 Pneumonia. J Am Soc Nephrol. 2020;31(6):1157-65. http://dx.doi.org/10.1681/ASN.2020030276.

3. Naicker S, Yang CW, Hwang SJ, Liu BC, Chen JH, Jha V. The Novel Coronavirus 2019 epidemic and kidneys. Kidney Int. 2020;97(5):8248. https://doi.org/10.1016/j.kint.2020.03.001.

4. Moore JB, June CH. Cytokine release syndrome in severe COVID-19. Science. 2020;368(6490):473-4. http://dx.doi.org/10.1126/ science.abb8925.

5. Husain-Syed F, Slutsky AS, Ronco C. Lung-Kidney Cross-Talk in the Critically Ill Patient. Am J Respir Crit Care Med. 2016;194(4):40214. http://dx.doi.org/10.1164/rccm.201602-0420CP.

6. Varga Z, Flammer AJ, Steiger P, Haberecker M, Andermatt R, Zinkernagel AS, et al. Endothelial cell infection and endotheliitis in COVID-19. Lancet. 2020;395(10234):1417-8. http://dx.doi.org/10.1016/S0140-6736(20)30937-5.

7. Su H, Yang M, Wan C, Yi LX, Tang F, Zhu HY, et al. Renal histopathological analysis of 26 postmortem findings of patients with COVID-19 in China. Kidney Int. 202;98(1):219-27. https://doi.org/10.1016/j.kint.2020.04.003.

8. Larsen CP, Bourne TD, Wilson JD, Saqqa O, Sharshir MA. Collapsing Glomerulopathy in a Patient With COVID-19. Kidney Int Rep. 2020;5(6):935-9: https://doi.org/10.1016/j.ekir.2020.04.002.

9. Delvaeye M, Conway EM. Coagulation and innate immune responses: can we view them separately? Blood. 2009;114(12):2367-74. https://doi.org/10.1182/blood-2009-05-199208.

10. Tang N, Li D, Wang X, Sun Z. Abnormal coagulation parameters are associated with poor prognosis in patients with novel coronavirus pneumonia. J Thromb Haemost. 2020;18(4):844-7. https://doi.org/10.1111/jth.14768.

11. Zhou F, Yu T, Du R, Fan G, Liu Y, Liu Z, et al. Clinical course and risk factors for mortality of adult inpatients with COVID-19 in Wuhan, China: a retrospective cohort study. Lancet. 2020;395(10229):1054-62. http://dx.doi.org/10.1016/S01406736(20)30566-3.

12. Diao B, Wang C, Feng Z, Tan Y, Wang H, Wang C, Liu L, et al. Human Kidney is a Target for Novel Severe Acute Respiratory Syndrome Coronavirus 2 (SARS-CoV-2) Infection. medRxiv. 2020. https://doi.org/10.1101/2020.03.04.20031120.

13. Li Z, Wu M, Yao J, Guo J, Liao X, Song S, et al. Caution on Kidney Dysfunctions of COVID-19 Patients. medRxiv. 2020. https:// doi.org/10.1101/2020.02.08.20021212.

14. Batlle D, Soler MJ, Sparks MA, Hiremath S, South AM, Welling PA, et al. Acute Kidney Injury in COVID-19: Emerging Evidence of a Distinct Pathophysiology. J Am Soc Nephrol]. 2020;31(7):1380-3. http://dx.doi.org/10.1681/ASN.2020040419.

15. Faubel S, Edelstein CL. Mechanisms and mediators of lung injury after acute kidney injury. Nat Rev Nephrol. 2016;12(1):48-60. http:/ /dx.doi.org/10.1038/nrneph.2015.158.

16. Alles A, Cueto-Manzano A, Ríos P, Robayo A, Sánchez-Polo V, Silvariño R, et al. Recomendaciones para el manejo de pacientes portadores de enfermedad renal frente a la epidemia de coronavirus (COVID-19). Ciudad de Panamá: Sociedad Latinoamericana de Nefrología e Hipertensión; 2020.

17. Ronco C, Reis T, Husain-syed F. Management of acute kidney injury in patients with COVID-19. Lancet Respir Med. 2020;8(70):73842. http://dx.doi.org/10.1016/S2213-2600(20)30229-0.

18. Joannidis M, Forni LG, Klein SJ, Honore PM, Kashani K, Ostermann M, et al. Lung-kidney interactions in critically ill patients: consensus report of the Acute Disease Quality Initiative (ADQI) 21 Workgroup. Intensive Care Med. 2020;46(4):654-72. http:// dx.doi.org/10.1007/s00134-019-05869-7.

19. Cheng Y, Luo R, Wang K, Zhang M, Wang Z, Dong L, et al. Kidney disease is associated with in-hospital death of patients with COVID19. Kidney Int. 2020;97(5):829-38. http://dx.doi.org/10.1016/j.kint.2020.03.005.

20. BRIGHAM AND WOMEN HOSPITAL. Nephrology. Acute Kidney Injury. 2020. /

21. Yang Y, Shi J, Ge S, Guo S, Xing X, Wang Y, et al. Effect of continuous renal replacement therapy on all-cause mortality in COVID19 patients undergoing invasive mechanical ventilation: a retrospective cohort study. medRxiv. 2020. https://doi.org/10.1101/ 2020.03.16.20036780.

22. Richardson S, Hirsch JS, Narasimhan M, Crawford JM, McGinn T, Davidson KW, et al. Presenting Characteristics, Comorbidities, and Outcomes Among 5700 Patients Hospitalized With COVID-19 in the New York City Area. JAMA. 2020;323(20):2052-9. https:// doi.org/10.1001/jama.2020.6775.

10 Consenso colombiano de expertos sobre recomendaciones informadas en la evidencia para la prevención... 
23. Hirsch JS, Ng JH, Ross DW, Sharma P, Shah HH, Barnett RL, et al. Acute kidney injury in patients hospitalized with COVID-19. Kidney Int. 2020;98(1):209-18. https://doi.org/10.1016/j.kint.2020.05.006.

24. Burgner A, Ikizler TA, Dwyer JP. COVID-19 and the Inpatient Dialysis Unit: Managing Resources During Contingency Planning PreCrisis. CJASN. 2020;15(5):720-2. https://doi.org/10.2215/CJN.03750320.

25. Acute RRT For Critically Ill Patients in ICU Settings During Respiratory Pandemic (SARS-CoV-2 [COVID-19], Pandemic Influenza, others). Emory Healthcare; 2020.

26. Yang X, Sun R, Dechang C. 新型冠状病毒肺炎诊治：急性肾损伤不容忽视.. Chin Med J (Engl). 2020;

27. Goldfarb DS, Benstein JA, Zhdanova O, Hammer E, Block CA, Caplin NJ, et al. Impending Shortages of Kidney Replacement Therapy for COVID-19 Patients. Clin J Am Soc Nephrol. 2020;15(6):880-2. https://doi.org/10.2215/CJN.05180420.

28. Molina-Andújar A, Blasco M, Poch E. Papel de la diálisis sostenida de baja eficiencia en las unidades de cuidados intensivos. Nefrología. 2009;39(1):1-3. http://dx.doi.org/10.1016/j.nefro.2018.06.002.

29. Palevsky PM, Radhakrishnan J, Townsend RR, Bakris GL, Forman JP. END-STAGE KIDNEY DISEASE. 2020;2019:1-18.

30. Aggarwal S, Garcia-Telles N, Aggarwal G, Lavie C, Lippi G, Henry BM. Clinical features, laboratory characteristics, and outcomes of patients hospitalized with coronavirus disease 2019 (COVID-19): Early report from the United States. Diagnosis (Berlin). 2020;7(2):916. http://dx.doi.org/10.1515/dx-2020-0046.

31. England. National Health Service (NHS). Clinical guide for acute kidney injury in hospitalised patients with COVID-19 outside the intensive care unit during the coronavirus pandemic. London: NHS; 2020.

32. Gebistorf F, Karam O, Wetterslev J, Afshari A. Inhaled nitric oxide for acute respiratory distress syndrome (ARDS) in children and adults. Cochrane Database Syst Rev. 2016;2016(6):CD002787. https://doi.org/10.1002/14651858.CD002787.pub3.

33. Alberici F, Delbarba E, Manenti C, Econimo L, Valerio F, Pola A, et al. Management of Patients on Dialysis and With Kidney Transplantation During the SARS-CoV-2 (COVID-19) Pandemic in Brescia, Italy. Kidney Int Reports. 2020;5(5):580-5. http:// dx.doi.org/10.1016/j.ekir.2020.04.001.

34. Vijayan A. Advice for Managing Acute Kidney Injury in COVID-19 Patients. Medscape. 2020.

35. Berhés M, Fábián Á, László I, Végh T, Molnár C, Fülesdi B, et al. Emelt szint? szervtámogató és életfenntartó kezelések kritikus állapotú COVID-19-fert?zött betegeken. Orvosi Hetilap. 2020;161(17):704-9. http://dx.doi.org/10.1556/650.2020.31813.

36. Chinese Medical Association. Expert consensus on the Application of Special Blood purification Technology in severe COVID-19 pneumonia. Chongqing; 2020.

37. Durvasula R, Wellington T, McNamara E, Watnick S. COVID-19 and Kidney Failure in the Acute Care Setting: Our Experience From Seattle. Am J Kidney Dis. 2020;76(1):4-6. http://dx.doi.org/10.1053/j.ajkd.2020.04.001.

38. Kielstein JT, Golper TA. Prolonged intermittent renal replacement therapy. UptoDate. 2020 [citado Ago 7 2020]; Disponible en: https://www.uptodate.com/contents/prolonged-intermittent-renal-replacement-therapy.

39. Alberici F, Delbarba E, Manenti C, Econimo L, Valerio F, Pola A, et al. Management of Patients on Dialysis and With Kidney Transplant During Covid- 19 Coronavirus Infection. Brescia Renal Covid Task Force; 2020 [citado 2020 Ago 5]. Disponible en: https:/ /www.era-edta.org/en/wp-content/uploads/2020/03/COVID_guidelines_finale_eng-GB.pdf.

40. Ye Q, Wang B, Mao J. The pathogenesis and treatment of the 'Cytokine Storm” in COVID-19. J Infect. 2020;80(6):607-13. https:/ /doi.org/10.1016/j.jinf.2020.03.037.

41. Fanelli V, Fiorentino M, Cantaluppi V, Gesualdo L, Stallone G, Ronco C, et al. Acute kidney injury in SARS-CoV-2 infected patients. Crit Care.2020;24(1):155. https://doi.org/10.1186/s13054-020-02872-z.

42. Yang XH, Sun RH, Zhao MY, Chen EZ, Liu J, Wang HL, et al. Expert recommendations on blood purification treatment protocol for patients with severe COVID-19: Recommendation and consensus. Chronic Dis Trans1 Med. 2020;6(2):106-14. https://doi.org/10.1016/ j.cdtm.2020.04.002,

43. Ye Q, Wang B, Mao J. Cytokine Storm in COVID-19 and Treatment. J Infect. 2020 Apr 1;

44. Ronco C, Reis T, De Rosa S. Coronavirus Epidemic and Extracorporeal Therapies in Intensive Care: Si vis pacem para bellum. Blood Purif. 2020;49(3):255-8. https://doi.org/10.1159/000507039.

45. Ikizler TA, Kliger AS. Minimizing the risk of COVID-19 among patients on dialysis. Nat Rev Nephrol. 2020;16(6):311-3. http:// dx.doi.org/10.1038/s41581-020-0280-y.

46. Adams E, Mousa AY. Achieving a Popliteal Venous Access for RRT in Critically Ill COVID-19 Patient in Prone position. J Vasc Surg Cases Innov Tech. 2020;6(2):266-8. https://doi.org/10.1016/j.jvscit.2020.04.003 


\section{Anexo A. Calidad de evidencia}

\begin{tabular}{|c|c|c|}
\hline Documento & $\begin{array}{c}\text { Tipo de } \\
\text { documento }\end{array}$ & $\begin{array}{l}\text { Evaluación } \\
\text { de calidad }\end{array}$ \\
\hline $\begin{array}{l}\text { Ronco C, Reis T. Kidney involvement in COVID-19 and rationale for } \\
\text { extracorporeal therapies. Nat Rev } \\
\text { http://dx.doi.org/10.1038/s41581-020-0284-7. }\end{array}$ & Comentario & N/A \\
\hline $\begin{array}{l}\text { Pei G, Zhang Z, Peng J, Liu L, Zhang C, Yu C, et al. Renal Involvement and Early } \\
\text { Prognosis in Patients with COVID-19 Pneumonia. J Am Soc Nephrol. } \\
\text { 2020;31(6):1157-65. http://dx.doi.org/10.1681/ASN.2020030276. }\end{array}$ & Serie de casos & $\begin{array}{l}\text { Cumple } \\
\text { reporte JBI }\end{array}$ \\
\hline $\begin{array}{l}\text { Naicker S, Yang CW, Hwang SJ, Liu BC, Chen JH, Jha V. The Novel Coronavirus } \\
2019 \text { epidemic and kidneys. Kidney Int. 2020;97(5):824-8. } \\
\text { https://doi.org/10.1016/j.kint.2020.03.001. }\end{array}$ & Revisión narrativa & N/A \\
\hline $\begin{array}{l}\text { Chinese Medical Association. Expert consensus on the Application of Special Blood } \\
\text { purification Technology in severe COVID-19 pneumonia. Chongqing; } 2020 .\end{array}$ & $\begin{array}{l}\text { Consenso de } \\
\text { expertos }\end{array}$ & N/A \\
\hline $\begin{array}{l}\text { Fanelli V, Fiorentino M, Cantaluppi V, Gesualdo L, Stallone G, Ronco C, et al. } \\
\text { Acute kidney injury in SARS-CoV-2 infected patients. Crit Care. 2020;24(1):155. } \\
\text { https://doi.org/10.1186/s13054-020-02872-z. }\end{array}$ & Com & N/A \\
\hline $\begin{array}{l}\text { Su H, Yang M, Wan C, Yi LX, Tang F, Zhu HY, et al. Renal histopathological } \\
\text { analysis of } 26 \text { postmortem findings of patients with COVID-19 in China. Kidney } \\
\text { Int. 2020; 98(1):219-27. https://doi.org/10.1016/j.kint.2020.04.003. }\end{array}$ & Serie de casos & $\begin{array}{l}\text { No c } \\
\text { repo }\end{array}$ \\
\hline 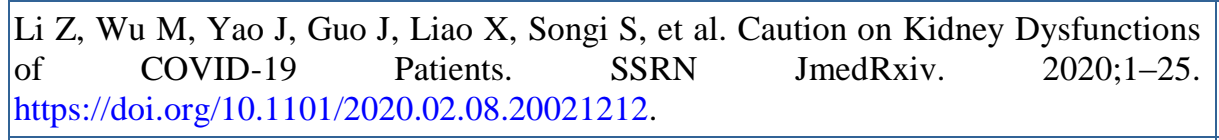 & Serie de casos & $\begin{array}{l}\text { No cumple } \\
\text { reporte JBI }\end{array}$ \\
\hline $\begin{array}{l}\text { Batlle D, Soler MJ, Sparks MA, Hiremath S, South AM, Welling PA, et al. Acute } \\
\text { Kidney Injury in COVID-19: Emerging Evidence of a Distinct Pathophysiology. J } \\
\text { Am Soc Nephrol. 2020;31(7):1380-3. http://dx.doi.org/10.1681/ASN.2020040419. }\end{array}$ & Punto de vista & N/A \\
\hline 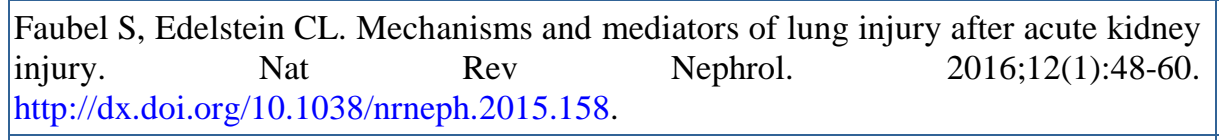 & Revisión narrativa & N/A \\
\hline $\begin{array}{l}\text { Alles A, Cueto-Manzano A, Ríos P, Robayo A, Sánchez-Polo V, Silvariño R, et al. } \\
\text { Recomendaciones para el manejo de pacientes portadores de enfermedad renal } \\
\text { frente a la epidemia de coronavirus (COVID-19). Ciudad de Panamá: Sociedad } \\
\text { Latinoamericana de Nefrología e Hipertensión; 2020. }\end{array}$ & Recomendaciones & N/A \\
\hline $\begin{array}{l}\text { Cheng Y, Luo R, Wang K, Zhang M, Wang Z, Dong L, et al. Kidney disease is } \\
\text { associated with in-hospital death of patients with COVID-19. Kidney Int. } \\
\text { 2020;97(5):829-38. http://dx.doi.org/10.1016/j.kint.2020.03.005. }\end{array}$ & $\begin{array}{l}\text { Cohorte } \\
\text { retrospectiva }\end{array}$ & $\begin{array}{l}\text { No cumple } \\
\text { reporte JBI }\end{array}$ \\
\hline BRIGHAM AND WOMEN HOSPITAL. Nephrology. Acute Kidney Injury. 2020. & Recomendaciones & $\begin{array}{l}\text { No cumple } \\
\text { reporte JBI }\end{array}$ \\
\hline $\begin{array}{l}\text { Yang Y, Shi J, Ge S, Guo S, Xing X, Wang Y, et al. Effect of continuous renal } \\
\text { replacement therapy on all-cause mortality in COVID-19 patients undergoing } \\
\text { invasive mechanical ventilation: a retrospective cohort study. medRxiv. } \\
2020 ; 21(1): 1-9 . \text { https://doi.org/10.1101/2020.03.16.20036780. }\end{array}$ & $\begin{array}{l}\text { Cohorte } \\
\text { retrospectiva }\end{array}$ & $\begin{array}{l}\text { No cumple } \\
\text { reporte JBI }\end{array}$ \\
\hline $\begin{array}{l}\text { Burgner A, Ikizler TA, Dwyer JP. COVID-19 and the Inpatient Dialysis Unit: } \\
\text { Managing Resources During Contingency Planning Pre-Crisis. CJASN. } \\
\text { 2020;15(5):720-2. https://doi.org/10.2215/CJN.03750320. }\end{array}$ & Punto de vista & N/A \\
\hline $\begin{array}{l}\text { Acute RRT For Critically Ill Patients in ICU Settings During Respirator } \\
\text { (SARS-CoV-2 [COVID-19], Pandemic Influenza, others). Emory Health }\end{array}$ & Recomendaciones & N/A \\
\hline
\end{tabular}

11 Consenso colombiano de expertos sobre recomendaciones informadas en la evidencia para la prevención... 


\begin{tabular}{|c|c|c|}
\hline Documento & $\begin{array}{c}\text { Tipo de } \\
\text { documento }\end{array}$ & $\begin{array}{l}\text { Evaluación } \\
\text { de calidad }\end{array}$ \\
\hline $\begin{array}{l}\text { Yang X, Sun R, Dechang C. 新型冠状病毒肺炎诊治 : 急性肾损伤不容忽视. } \\
\text { Chin Med J (Engl). 2020; }\end{array}$ & Reporte de caso & $\begin{array}{l}\text { Cumple } \\
\text { reporte JBI }\end{array}$ \\
\hline $\begin{array}{l}\text { Goldfarb DS, Benstein JA, Zhdanova O, Hammer E, Block CA, Caplin NJ, et al. } \\
\text { Impending Shortages of Kidney Replacement Therapy for COVID-19 Patients. Clin } \\
\text { J Am Soc Nephrol. 2020;15(6):880-2. https://doi.org/10.2215/CJN.05180420. }\end{array}$ & Punto de vista & N/A \\
\hline $\begin{array}{l}\text { Molina-Andújar A, Blasco M, Poch E. Papel de la diálisis sostenida de baja } \\
\text { eficiencia en las unidades de cuidados intensivos. Nefrología. 2009;39(1):1-3. } \\
\text { http://dx.doi.org/10.1016/j.nefro.2018.06.002. }\end{array}$ & Carta al editor & N/A \\
\hline $\begin{array}{l}\text { Palevsky PM, Radhakrishnan J, Townsend RR, Bakris GL, Forman JP. END- } \\
\text { STAGE KIDNEY DISEASE. 2020;2019:1-18. }\end{array}$ & Recomendaciones & N/A \\
\hline $\begin{array}{l}\text { Aggarwal S, Garcia-Telles N, Aggarwal G, Lavie C, Lippi G, Henry BM. Clinical } \\
\text { features, laboratory characteristics, and outcomes of patients hospitalized with } \\
\text { coronavirus disease } 2019 \text { (COVID-19): Early report from the United States. } \\
\text { Diagnosis (Berlin). 2020;7(2):91-6. http://dx.doi.org/10.1515/dx-2020-0046. }\end{array}$ & Serie de casos & $\begin{array}{l}\text { Cumple } \\
\text { reporte JBI }\end{array}$ \\
\hline $\begin{array}{l}\text { England. National Health Service (NHS). Clinical guide for acute kidney injury in } \\
\text { hospitalised patients with COVID-19 outside the intensive care unit during the } \\
\text { coronavirus pandemic. London: NHS; } 2020 ; \text {; }\end{array}$ & Guía clínica & Baja \\
\hline $\begin{array}{l}\text { Diao B, Wang C, Feng Z, Tan Y, Wang H, Wang C, Liu L, et al. Human Kidney is } \\
\text { a Target for Novel Severe Acute Respiratory Syndrome Coronavirus } 2 \text { (SARS-CoV- } \\
\text { 2) Infection. medRxiv. 2020. https://doi.org/10.1101/2020.03.04.20031120. }\end{array}$ & Serie de casos & $\begin{array}{l}\text { No cumple } \\
\text { reporte JBI }\end{array}$ \\
\hline $\begin{array}{l}\text { Gebistorf F, Karam O, Wetterslev J, Afshari A. Inhaled nitric oxide for acute } \\
\text { respiratory distress syndrome (ARDS) in children and adults. Cochrane Database } \\
\text { Syst } \\
\text { hev. } \\
\text { https://doi.org//10.1002/14651858.CD002787.pub3. }\end{array}$ & $\begin{array}{l}\text { Revisión } \\
\text { sistemática de la } \\
\text { literatura }\end{array}$ & Alta \\
\hline $\begin{array}{l}\text { Alberici F, Delbarba E, Manenti C, Econimo L, Valerio F, Pola A, et al. } \\
\text { Management of Patients on Dialysis and With Kidney Transplantation During the } \\
\text { SARS-CoV-2 (COVID-19) Pandemic in Brescia, Italy. Kidney Int Reports. 2020; } \\
\text { 5(5):580-5. http://dx.doi.org/10.1016/j.ekir.2020.04.001. }\end{array}$ & Punto de vista & N/A \\
\hline $\begin{array}{l}\text { Vijayan A. Advice for Managing Acute Kidney Injury in COVID-19 Patients. } \\
\text { Medscape; } 2020 .\end{array}$ & Punto de vista & N/A \\
\hline $\begin{array}{l}\text { Joannidis M, Forni LG, Klein SJ, Honore PM, Kashani K, Ostermann M, et al. } \\
\text { Lung-kidney interactions in critically ill patients: consensus report of the Acute } \\
\text { Disease Quality Initiative (ADQI) 21 Workgroup. Intensive Care Med. } \\
\text { 2020;46(4):654-72. https://doi.org/10.1007/s00134-019-05869-7. }\end{array}$ & $\begin{array}{l}\text { Consenso de } \\
\text { expertos }\end{array}$ & N/A \\
\hline $\begin{array}{l}\text { Berhés M, Fábián Á, László I, Végh T, Molnár C, Fülesdi B, et al. Emelt szintü } \\
\begin{array}{l}\text { szervtámogató és életfenntartó kezelések kritikus állapotú COVID-19-fertőzött } \\
\text { betegeken. } \\
\text { http://dx.doi.org/10.1556/650.2020.31813. }\end{array} \\
\end{array}$ & Revisión narrativa & N/A \\
\hline $\begin{array}{l}\text { Alberici F, Delbarba E, Manenti C, Econimo L, Valerio F, Pola A, et al. } \\
\text { Management of Patients on Dialysis and With Kidney Transplant During Covid- } 19 \\
\text { Coronavirus Infection. Brescia Renal Covid Task Force; } 2020 \text { [citado } 2020 \text { Ago 5]. } \\
\begin{array}{l}\text { Disponible hter://www.era-edta.org/en/wp- } \\
\text { content/uploads/2020/03/COVID_guidelines_finale_eng-GB.pdf. }\end{array}\end{array}$ & Punto de vista & N/A \\
\hline $\begin{array}{l}\text { Durvasula R, Wellington T, McNamara E, Watnick S. COVID-19 and Kidney } \\
\text { Failure in the Acute Care Setting: Our Experience From Seattle. Am JKidney Dis. } \\
\text { 2020;76(1):4-6. http://dx.doi.org/10.1053/j.ajkd.2020.04.001. }\end{array}$ & Editorial & N/A \\
\hline
\end{tabular}

González C, Yama E, Yomayusa N, Vargas J, Rico J, Ariza A, Aroca G, Baquero R, Ramírez R, et al. 
Continuación ANEXO A.

\begin{tabular}{|c|c|c|}
\hline Documento & $\begin{array}{c}\text { Tipo de } \\
\text { documento }\end{array}$ & $\begin{array}{l}\text { Evaluación } \\
\text { de calidad }\end{array}$ \\
\hline 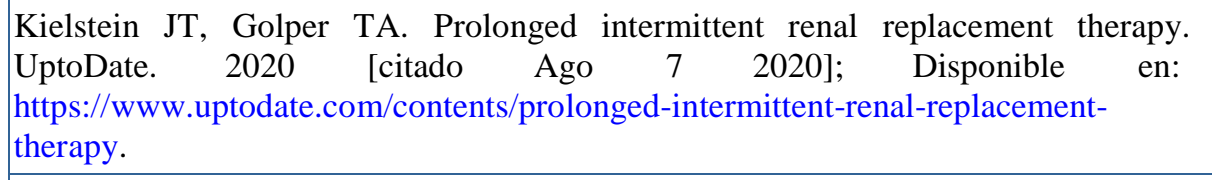 & Revisión narrativa & N/A \\
\hline $\begin{array}{l}\text { Ye,Q Wang B, Mao J. The pathogenesis and treatment of the 'Cytokine Storm', in } \\
\text { COVID-19.' J Infect [Internet]. } \\
\text { https://doi.org/10.1016/j.jinf.2020.03.037. }\end{array}$ & Revisión & N/A \\
\hline $\begin{array}{l}\text { Zhou F, Yu T, Du R, Fan G, Liu Y, Liu Z, et al. Clinical course and risk factors for } \\
\text { mortality of adult inpatients with COVID-19 in Wuhan, China: a retrospective } \\
\text { cohort study. Lancet. 2020;395(10229):1054-62. http://dx.doi.org/10.1016/S0140- } \\
6736(20) 30566-3 \text {. }\end{array}$ & Estudio de cohorte & Moderada \\
\hline $\begin{array}{l}\text { Yang XH, Sun RH, Zhao MY, Chen EZ, Liu J, Wang HL, et al. Expert } \\
\text { recommendations on blood purification treatment protocol for patients with severe } \\
\text { COVID-19: Recommendation and consensus. Chronic Dis Transl Med. } \\
\text { 2020;6(2):106-14. https://doi.org/10.1016/j.cdtm.2020.04.002. }\end{array}$ & $\begin{array}{l}\text { Consenso } \\
\text { informal de } \\
\text { expertos }\end{array}$ & N/A \\
\hline $\begin{array}{l}\text { Ye Q, Wang B, Mao J. Cytokine Storm in COVID-19 and Treatment. J Infect. } 2020 \\
\text { Apr 1; }\end{array}$ & Revisión narrativa & N/A \\
\hline $\begin{array}{l}\text { Ronco C, Reis T, De Rosa S. Coronavirus Epidemic and Extracorporeal Therapies } \\
\text { in Intensive Care: Si vis pacem para bellum. Blood Purif. 2020;49(3):255-8. } \\
\text { https://doi.org/10.1159/000507039. }\end{array}$ & Editorial & N/A \\
\hline $\begin{array}{l}\text { Ronco C, Reis T, Husain-syed F. Management of acute kidney injury in patients } \\
\text { with } \quad \text { COVID-19. Lancet } \quad \text { Respir } \quad \text { Med. } \\
\text { http://dx.doi.org/10.1016/S2213-2600(20)30229-0. }\end{array}$ & Punto de vista & N/A \\
\hline $\begin{array}{l}\text { Ikizler TA, Kliger AS. Minimizing the risk of COVID-19 among patients on } \\
\text { dialysis. Nat Rev Nephrol. 2020;16(6):311-3. http://dx.doi.org/10.1038/s41581-020- } \\
\text { 0280-y. }\end{array}$ & Comentario & N/A \\
\hline $\begin{array}{l}\text { Adams E, Mousa AY. Achieving a Popliteal Venous Access for RRT in Critically } \\
\text { Ill COVID-19 Patient in Prone position. J Vasc Surg Cases Innov Tech. } \\
2020 ; 6(2): 266-8 \text {. https://doi.org/10.1016/j.jvscit.2020.04.003. }\end{array}$ & Repo & $\begin{array}{l}\text { Cumple } \\
\text { reporte JBI }\end{array}$ \\
\hline
\end{tabular}

JBI: desarrollar

11 Consenso colombiano de expertos sobre recomendaciones informadas en la evidencia para la prevención... 


\section{Anexo B. Resultados de consulta por recomendación}

Emplear como definición de LRA la establecida por el consorcio KDIGO: aumento de los niveles de creatinina sérica por encima de $0,3 \mathrm{mg} / \mathrm{dL}$ en 48 horas a pesar de una adecuada reanimación, o un aumento de más del $50 \%$ respecto al valor de base en los últimos 7 días o volumen de orina $<0,5$ 97.96 $\mathrm{mL} / \mathrm{kg} /$ hora durante 6 horas

Clasificar la severidad de la LRA asociada a COVID-19 según la recomendación vigente del consorcio KDIGO.

100.00

Considerar como factores de riesgo de LRA asociada a COVID-19 edad avanzada; comorbilidades como hipertensión, diabetes y enfermedad cardiovascular; requerimiento de ventilación mecánica; hipovolemia; choque; uso de medicamentos nefrotóxicos, e inhalación de óxido nítrico.

Considerar la LRA dentro de los factores pronóstico de COVID-19.

100.00

Considerar como factores pronóstico de LRA en pacientes con COVID-19 a la necesidad de ventilación mecánica y de TSR, a los eventos de coagulación del sistema de soporte renal, a la proteinuria a y la presencia de complicaciones como hipercalemia, acidemia y sobrecarga de fluidos.

Optimizar el volumen para garantizar la perfusión renal mediante medidas convencionales de respuesta según las recomendaciones vigentes y la disponibilidad en cada centro de atención.]

Analizar de manera individualizada la conveniencia de realizar reanimación con líquidosevaluando riesgos-beneficios, esto con el fin de evitar sobrecarga de fluidos.

Evitar, en la medida de lo posible, medicamentos nefrotóxicos como antiinflamatorios no esteroideos, bloqueadores del eje renina angiotensina aldosterona, medios de contraste iodados, aminoglucósidos, vancomicina, entre otros.

Hacer una evaluación y un seguimiento estandarizado de la función renal en pacientes hospitalizados con COVID-19, incluyendo control diario de creatinina en sangre y monitoreo de gasto urinario.

Hacer un control estricto del balance de líquidos y un monitoreo de electrolitos para mitigar la indicación de terapia de soporte renal anticipada, la cual es producto de complicaciones prevenibles o adquiridas por el manejo farmacológico de la COVID-19.

Prevenir hipercalemia en pacientes con COVID-19.

Realizar ventilación mecánica protectora para mitigar barotraumas y volutraumas, los cuales tienen repercusiones renales.

Considerar el uso de diuréticos de asa para el manejo de balance de fluidos.

Determinar, por parte del nefrólogo, la necesidad, el momento y la modalidad del reemplazo renal evaluando cada paciente de manera aislada y con base en los estándares de soporte renal vigente. Considerar las indicaciones habituales de soporte renal para pacientes con COVID-19.

Iniciar TSR en paciente con LRA y COVID-19 con complicaciones como hiperpotasemia, acidemia metabólica, sobrecarga de volumen y manifestaciones urémicas.

Iniciar TSR en pacientes COVID-19 y LRA en estadio 3 según los criterios establecidos por el consorcio KDIGO y considerando el contexto clínico más amplio (presencia de afecciones modificables con la terapia, y las tendencias de los laboratorios), más allá de un valor de creatinina o BUN.

Discutir entre especialistas de las áreas de cuidado intensivo, nefrología, enfermería y el paciente o sus familiares la decisión de iniciar la TSR y la modalidad de elección teniendo en cuenta los recursos disponibles.

Usar la TRRC o la TRRIP como la modalidad de primera línea en el manejo de pacientes con LRA y COVID-19 críticamente enfermo, pues tienen una mejor capacidad de remoción de fluidos y mejor tolerancia hemodinámica. 


\section{Continuación ANEXO B.}

\section{Recomendación}

Usar dosis aportada de $20-25 \mathrm{~mL} / \mathrm{kg} / \mathrm{h}$ (prescrita $25-30 \mathrm{~mL} / \mathrm{kg} /$ día) para la modalidad TRRC y realizar los ajustes según el estado metabólico.

Formular diariamente y en equipo multidisciplinario las metas de la TSR diariamente, aunque la responsabilidad de la dosificación de la modalidad es siempre del nefrólogo.

Usar la modalidad de hemodiafiltración veno-venosa continua o hemodiálisis veno-venosa sobre la hemofiltración en caso de LRA secundaria a COVID-19 para disminuir la fracción de filtración y mejorar la durabilidad del circuito.

Capacitar a todo el personal de enfermería de UCI para proporcionar TRRC a pacientes con LRA y COVID-19.

En caso de aumento de demanda de diálisis y una capacidad reducida, considerar la modalidad TRRIP, inclusive usando los dispositivos de TRRC para lograr un alcance de dos a tres pacientes por día por dispositivo.

En caso de indicación de TRRIP, usar una dosis mínima entre $40-80 \mathrm{~mL} / \mathrm{kg} / \mathrm{h}$ durante 6 a 12 horas.

En centros sin disponibilidad de TRRC o TRRIP o con baja experiencia con estos dispositivos, proceder con HDI o diálisis peritoneal.

97.96

Considerar la diálisis peritoneal aguda alternativa de TSR en paciente con LRA y COVID-19 cuando no sea posible aplicar otra modalidad o para aliviar la carga de trabajo del personal encargado de hemodiálisis u otras modalidades.

Preferir el uso de diálisis peritoneal automatizada sobre la manual cuando sea posible en pacientes con COVID-19.

Extremar las medidas de bioseguridad durante los intercambios manuales de dializado.

Tener en cuenta la remoción de medicamentos por las distintas terapias y realizar los ajustes correspondientes a la dosificación de los mismos según las capacidades de aclaramiento esperadas o identificadas.

Controlar los electrolitos mínimo una vez al día durante la terapia, y más frecuente si es necesario según criterio médico y cambios asociados con las distintas terapias.

Hacer seguimiento del equilibrio acido-base y del índice de coagulación más de una vez al día.

Hacer seguimiento de las imágenes de tórax al menos cada tercer día.

Preferir la modalidad de TRRC como primera línea de manejo indicado con terapias extracorpóreas en pacientes COVID-19 y LRA en presencia de síndrome por tormenta de citoquinas.

Considerar las terapias de purificación extracorpórea en pacientes graves con COVID-19, para eliminar citoquinas en el síndrome por tormenta de citoquinas, cuando las terapias convencionales 95.92 estén fallen o sean insuficientes, siempre evaluando el pronóstico individual de cada paciente.

No usar de forma masiva las terapias de purificación sanguínea en infección por SARS-CoV-2 severa ya que la evidencia en choque séptico es inconclusa.

No usar de manera rutinaria el recambio plasmático terapéutico en casos de COVID-19 severo; sin embargo, en centros con alta experiencia puede ser usado cuidadosamente en casos específicos evaluando riesgos-beneficios y pronóstico individual.

Emplear como criterios para considerar las terapias de remoción de citoquinas en pacientes con COVID-19 grave: la presencia de LRA estadio $\geq 2$ según criterios del consorcio KDIGO, SDRA severo, choque, y manifestaciones de síndrome de tormenta por citoquinas como fiebre persistente, IL 6 elevada, hipoalbuminemia, ferritina elevada y proteína c-reactiva. 
Continuación ANEXO B.

Emplear estrategias de anticoagulación durante los procedimientos de TSR en pacientes con COVID-19 para prevenir la coagulación del circuito.

95.92

Usar el mecanismo de anticoagulación con el que el centro de atención siguiendo los

requerimientos específicos de cada paciente.

100.00

Considerar el riesgo de sangrado o sangrado activo antes de implementar los protocolos de anticoagulación.

Considerar heparinización sistémica cuando el protocolo de citratos falle o cuando esta estrategia no esté disponible.

Garantizar durante la TSR un flujo sanguíneo $>120 \mathrm{~mL} / \mathrm{min}$ para evitar coagulación del circuito, independientemente del protocolo de anticoagulación implementado.

Usar protocolos de anticoagulación con citratos como estrategia de primera línea en la prevención de coagulación del circuito.

En el caso de Implementar protocolo de citratos, realizar seguimiento estricto mínimo cada 12 horas de los niveles de calcio iónico sistémico y calcio total del paciente del circuito y de los cambios en $\mathrm{pH}$ arterial.

En caso de Implementar protocolo de heparina no fraccionada, monitorización el aTTP para metas de entre 60 y 90 segundos y según disponibilidad antitrombina III. Este último especialmente si se denota coagulación temprana recurrente y no explicada de circuitos de TRRC o TRRIP.

No implementar protocolos de anticoagulación novedosos y diferentes a los de la práctica rutinaria durante la TSR.

Garantizar que el implante de acceso vascular lo realice un equipo de salud experto para minimizar el riesgo de complicaciones.

Garantizar que la colocación del catéter sea guiada por ultrasonido.

100.00

Garantiza que el personal de salud involucrado en la colocación del catéter siga las recomendaciones de bioseguridad y utilice EPP .

95.92

91.84

75.51

Realizar una planeación del acceso vascular de TSR considerando la necesidad de ventilación mecánica, la localización de dispositivos de invasión y el requerimiento de posición prono en casos graves de COVID-19.

Garantizar que el acceso vascular se implante en la vena yugular interna derecha como primera opción.

Realizar control de radiografía de tórax después de implantar catéter yugular para TSR.

91.84

Evitar el acceso subclavio y yugular izquierdo.

97.96

En caso de ser necesario, considerar como segunda opción de acceso vascular la vena femoral derecha, teniendo en consideración los factores de riesgo para sobreinfección como obesidad y presencia de diarrea.]

En pacientes con LRA por SARS COV-2 y en manejo con ECMO, establecer la conexión del dispositivo externo de soporte renal al circuido de oxigenación. Sin embargo, ante la evidencia o alta probabilidad de formación de coágulos en el circuito de ECMO, se debe establecer un acceso individual para la TSR.

Seguir las medidas universales de lavado de manos en cinco momentos de la atención y usar de manera racional y correcta los EPP.

Aplicar TSR en pacientes COVID-19 en habitación o salas para evitar el desplazamiento por la institución. 
Continuación ANEXO B.

Recomendación

Resultado consulta $(\%)$

Realizar los protocolos de limpieza y desinfección de las máquinas de TSR al finalizar los procedimientos.

Limpiar y desinfectar con solución clorada y una vez por turno la máquina de TSR, la mesa de tratamiento y los elementos utilizados durante la terapia.

Seguir los protocolos institucionales de desechos de material contaminado por COVID-19 y reforzar la desinfección con solución clorada y el etiquetado de las bolsas que contienen dicho material.

Realizar la disposición de líquidos de TSR siguiendo protocolo institucional y minimizando la generación de microgotas, gotas y aerosoles.

No usar circuitos de sangre largos, a pesar de que permitan ubicar las máquinas de TSR fuera de las habitaciones, como medida de prevención de contagio entre personal.

100.00

Dar continuidad al tratamiento de remplazo renal de base para ERC estadio 5 durante la estancia hospitalaria en cuidado crítico o sala general por COVID-19.

Dar continuidad a la diálisis peritoneal en pacientes con TSR por ERC estadio 5, en la medida de lo posible.

Preferir la diálisis peritoneal automatizada en pacientes bajo tratamiento de remplazo renal con diálisis peritoneal manual de base.

95.92

Evitar el uso de la fístula arteriovenosa como acceso para TRRC, o para TRRIP con tiempos de tratamiento $>6$ horas.

11 Consenso colombiano de expertos sobre recomendaciones informadas en la evidencia para la prevención... 


\section{Anexo C. Grupo desarrollador}

Dirección del consenso

Nancy Yomayusa

Comité directivo consenso

Nancy Yomayusa, Gustavo Aroca, Richard Baquero, Erica Yama, Camilo González, Adriana Robayo, Amaury Ariza, Juan Guillermo Vargas, Jorge Rico, Roberto Ramírez, Rodolfo Torres

\section{Comité metodológico Kelly Chacón}

\section{Comités de expertos clínicos}

\section{Capítulo I: Diálisis}

Coordinadores: Erika Yama, Amaury Ariza.

Erica Yama, Amaury García, Jorge Coronado, Javier Galeano, Luis Barros, Alfonso Brunch Mauricio Sanabria, Jesús Muñoz, Benjamín Wancjer, Juan Carlos Alarcón, Rafael Gómez, Freddy Ardila, Alfonso Bunch, Luis Alfonso Valderrama, Leonardo Hernández, María Inés Gómez, Huber Sánchez, Diego Benavides, Francisco López, Andrés Díaz, Alberto Yunez, Marco Anaya, Huber Sánchez, Mauricio Ruiz.

\section{Capítulo II: Lesión Renal Aguda}

Coordinadores: Camilo González, Juan Guillermo Vargas, Jorge Rico.

Camilo González, Jorge Echeverri, Jorge Rico, Juan Guillermo Vargas, David Ballesteros, Manuel Huérfano, Mauricio Guerrero, Guillermo Pinzón, Greissy Gonzales, Leonardo Marín, Carlos Lozano, Helman Benavides, Alejandra Molano, Andrea Caicedo, Manuel Huérfano, Richard Baquero, Adalberto Peña, Alexandra Lizarazo, Andrés Díaz, David Ballesteros, Diana Vargas, Jhon Serna, Emir Ortiz, Enrique Benavidez, Jorge Pulido, Jorge Mora, María José Vargas, Paula Rodríguez, Kateir Contreras, Mauricio Guerrero, Rodrigo Daza, Sandra Juliana Jiménez, Adriana Robayo, Gabriel Cantor.

\section{Capítulo III: Nefrología Pediátrica: Coordinador: Richard Baquero.}

Natalia Mejía, Jimena Cáceres, Diana Carolina Chacón Jaimes, Ehimy Suarez Barajas, Richard Baquero, Natalia Mejía, Jimena Cáceres, Ehimy Suarez Barajas, Angélica María Calderón Ortiz, Adriana Isabel Meza Martínez, Carolina Lucia Ochoa, Douglas Ramón Villafañe Bermúdez, Zilac Espitaleta, Gustavo Guerrero Tinoco, Martha Isabel Carrascal.

\section{Capítulo IV: Adulto Mayor y Multimorbido: Coordinador: Roberto Ramírez.} Joaquín Rodelo, Héctor Mauricio Cárdenas, Álvaro Mercado, Hernando Altahona, Sandra Castelo, Mercedes Alfaro, Inge Arroyabe, Viviana Raoch, Elizabeth Ardila, Claudia Acosta, Roberto Ramírez, Ignacio Villanueva.

\section{Capítulo V: Trasplante y Enfermedad Glomerular: Coordinador: Rodolfo Torres.} Camilo Montero, Paola García, Andrés Acevedo, Rodolfo Torres, Gustavo Aroca, Astrid Hernández, Orlando Olivares, Natalia Malaver, Jessica Pinto, Sandra Juliana Jiménez, Gustavo Aroca, Marco Anaya, Sonia Celi.

\section{Capítulo VI: Enfermería Nefrológica}

Coordinadores: Diana Gayón, Jorge Pérez Ingrid Torres, Carolina Pedraza, Natalia Carolina Tobón, Betty Zambrano, Jeniffer Fordon, Liseth Rincón, María Fernanda Pérez, Luisa Fernanda Grajales, Luis Chaparro Quiroz

Equipo técnico-científico multidisciplinar

\section{Geriatría}

Héctor Mauricio Cárdenas. Asociación Colombiana de Geriatría

Nefrogeriatría

Carlos Guido Musso. Argentina

Cuidado Paliativo

Sandra Liliana Parra, Paola Marcela Ruiz, María Victoria Mera, Gabriela Sarmiento.

\section{Infectología Pediátrica}

Sandra Beltrán

Ministerio de Salud: Álvaro Burgos 